NBER WORKING PAPER SERIES

\title{
STRATEGIC PATIENT DISCHARGE: \\ THE CASE OF LONG-TERM CARE HOSPITALS
}

\author{
Paul J. Eliason \\ Paul L. E. Grieco \\ Ryan C. McDevitt \\ James W. Roberts \\ Working Paper 22598 \\ http://www.nber.org/papers/w22598
NATIONAL BUREAU OF ECONOMIC RESEARCH
1050 Massachusetts Avenue
Cambridge, MA 02138 \\ September 2016
}

Martin Gaynor, Ben Handel, and numerous seminar participants provided helpful comments. Dan Chen and Carla Rodriguez provided excellent research assistance. The views expressed herein are those of the authors and do not necessarily reflect the views of the National Bureau of Economic Research.

NBER working papers are circulated for discussion and comment purposes. They have not been peerreviewed or been subject to the review by the NBER Board of Directors that accompanies official NBER publications.

(C) 2016 by Paul J. Eliason, Paul L. E. Grieco, Ryan C. McDevitt, and James W. Roberts. All rights reserved. Short sections of text, not to exceed two paragraphs, may be quoted without explicit permission provided that full credit, including $\odot$ notice, is given to the source. 
Strategic Patient Discharge: The Case of Long-Term Care Hospitals

Paul J. Eliason, Paul L. E. Grieco, Ryan C. McDevitt, and James W. Roberts

NBER Working Paper No. 22598

September 2016, Revised January 2017

JEL No. D22,I11,I18

\begin{abstract}
$\underline{\text { ABSTRACT }}$
Medicare's prospective payment system for long-term acute-care hospitals (LTCHs) pro- vides modest reimbursements at the beginning of a patient's stay before jumping discontinuously to a large lump-sum payment after a pre-specified number of days. We show that LTCHs respond to financial incentives by disproportionately discharging patients after they cross the large-payment threshold, resulting in worse outcomes for patients. We find this occurs more often at for-profit facilities, facilities acquired by leading LTCH chains, and facilities co-located with other hospitals. Using a dynamic structural model, we evaluate counterfactual payment policies that would provide substantial savings for Medicare without adversely affecting patients.

\author{
Paul J. Eliason \\ Duke University \\ Department of Economics \\ 213 Social Sciences Building \\ Durham, NC 27708 \\ paul.eliason@duke.edu \\ Paul L. E. Grieco \\ The Pennsylvania State University \\ Department of Economics \\ 509 Kern Building \\ University Park \\ Pennsylvania, PA 16802, USA \\ paul.grieco@gmail.com
}

Ryan C. McDevitt

Duke University, The Fuqua School of Business

Department of Economics

100 Fuqua Drive

Durham, NC

27708

ryan.mcdevitt@duke.edu

James W. Roberts

Duke University

Department of Economics

213 Social Sciences Building

Durham, NC 27708

and NBER

j.roberts@duke.edu
\end{abstract}




\section{Introduction}

Medicare strives to enact policies that balance costs and quality. One prominent effort aimed at achieving this elusive goal is the prospective payment system (PPS) that gives hospitals a fixed, predetermined reimbursement for each patient's stay. An advantage of this system is that it provides an incentive to deliver care efficiently, as extraneous procedures and tests would increase hospitals' costs but not yield any additional revenue. One drawback of such a policy, however, is that hospitals may base their decisions not on clinical guidelines for effective care, but on maximizing their reimbursements given the financial incentives of the payment system.

In this paper, we examine an inpatient hospital segment heavily influenced by Medicare's PPS, long-term acute-care hospitals (LTCHs), and show that hospitals disproportionately discharge patients when it is most profitable for them to do so rather than when it is most beneficial for the patient. As a result, the average LTCH keeps patients about a week longer than they would if they based discharge decisions solely on the cost of providing care and other non-pecuniary factors. Such longer stays not only harm patients by increasing their risk of contracting infections or dying at the hospital, but also impose a wasteful financial burden on Medicare. We show that a recently proposed change to the reimbursement system would dampen hospitals' incentives to keep patients in their facilities for purely financial reasons and would have reduced Medicare's payments to LTCHs by hundreds of millions of dollars over the ten years we study.

Long-term care hospitals specialize in treating patients with serious medical conditions who require prolonged care. As an organizational form, LTCHs exist largely as a response to the PPS Medicare introduced for general acute-care hospitals in the 1980s. Under this system, traditional hospitals often lose money on patients who stay for extended periods, giving them an incentive to discharge patients to LTCHs that then receive new Medicare payments upon admission that is, both hospitals benefit financially. Such an arrangement directly impacts the largest segment of Medicare spending, as both traditional and long-term acute-care hospitals receive reimbursements under Medicare Part A, for which spending on all inpatient stays exceeded $\$ 145$ billion in 2015.1]

Under the current PPS, Medicare reimburses LTCHs a fixed amount per admission based on the patient's diagnosis-related group (DRG), and these per-stay reimbursements are substantially larger than those for general acute-care hospitals.2 To discourage LTCHs from exploiting their higher reimbursement status by admitting patients who would be better suited for a traditional acute-care hospital, Medicare classifies patients as short-stay outliers (SSOs) if they stay fewer than a pre-specified number of days based on their DRG and reimburses LTCHs significantly less for these patients.

\footnotetext{
${ }^{1}$ Budget in Brief, Department of Health and Human Services, FY 2015 (http://www.hhs.gov/about/budget/ fy2015/budget-in-brief/cms/medicare/index.html).

${ }^{2}$ We focus on Medicare patients in this paper as they make up the bulk of LTCH patients (see Section 2 below).
} 
Having reimbursements depend on a patient crossing a threshold for her length of stay results in a narrow window during which an LTCH achieves maximum profitability for each patient. In response to this financial incentive, LTCHs often discharge patients immediately after they cross the SSO threshold, which industry participants have dubbed the "magic day" (Berenson 2/9/2010). This suggests that the financial incentives created by Medicare's payment system may inadvertently shape patient care: keeping patients longer than medically necessary represents poor quality care due to both the psychological burden a patient experiences by remaining at a hospital and the increased health risks associated with infections and medical errors, whereas prematurely discharging a patient simply because she has reached the magic day could mean that she has not yet received adequate treatment.

Previous reports suggest that corporate executives pressure LTCH administrators to discharge patients immediately after they pass the SSO threshold. A 2015 Wall Street Journal article (Weaver et al. 2/17/2015), for instance, described meetings at which hospital staffers would discuss treatment plans, "armed with printouts from a computer tracking system that included, for each patient, the date at which reimbursement would shift to a higher, lump-sum payout." Reports also allege that LTCH administrators "sometimes ordered extra care or services intended in part to retain patients until they reached their thresholds, or discharged those who were costing the hospitals money regardless of whether their medical conditions had improved," while "bonuses depended in part on maintaining a high share of patients discharged at or near the threshold dates to meet earnings goals."

Given the financial incentives created by Medicare's PPS, our paper examines the prevalence of strategic discharging at LTCHs ${ }^{3}$ Using Medicare claims data from fiscal years 2004-2013, we first provide descriptive evidence that LTCHs are much more likely to discharge patients during the window immediately after they cross the threshold for lump-sum payments compared to what would be expected if patients were discharged based solely on clinical measures. To identify this practice, we exploit the sharp discontinuity in payments around the SSO threshold, finding that LTCHs discharged 25.7 percent of patients during the three days immediately after crossing the threshold compared to 6.8 percent of patients in the three days immediately preceding it.

Based on the anecdotal evidence referenced above, this nearly fourfold increase in discharges for patients just past the SSO threshold would seem to stem largely from the strategic behavior of LTCHs. To cleanly link it to Medicare's reimbursement policy, however, we must first overcome several empirical challenges. For one, we do not observe many of the factors that influence hospitals' discharge decisions, such as a patient's desire to be released or the full extent of her medical needs. To establish that the link between the PPS and strategic discharging is causal, we therefore exploit several key sources of variation in the data. Most importantly, the SSO

\footnotetext{
${ }^{3}$ We use the term "strategic discharge" to refer to cases where patients are discharged for financial reasons rather than clinical ones.
} 
threshold varies across DRGs within a year and within a DRG across years. Using both this time-series and cross-sectional variation, we consistently find that LTCHs discharge patients on the magic day for any given DRG in any given year. Furthermore, if facilities discharged patients purely for clinical reasons, we would expect to observe a smooth distribution of discharges over the length of patients' stays; instead, we observe a discontinuous jump in discharges on the magic day that corresponds to the discontinuous jump in payments. We also show that in 2002, when the current PPS system was not in place — and thus LTCHs did not face a discontinuity in the reimbursement schedule - discharges had no discernible spike around what would become the magic days in later years.

Another threat to identification is that discharges could cluster on the magic day simply because the SSO threshold is based on a DRG's average length of stay and patients with similar diagnoses undergo similar treatments. The strong association we find between the timing of discharges and the financial motives of providers suggests that this type of coincidence is not driving our results. For instance, we show that a patient is more likely to be released on the magic day if her DRG has a larger lump-sum payment. In addition, we show that discharges of patients to their homes — which are the easiest type of discharge to manipulate - exhibit the clearest evidence of strategic behavior, whereas discharges due to death are unrelated to reimbursements, a key falsification test. We also find that for-profit hospitals are more likely to engage in strategic discharge than non-profit hospitals, as are facilities co-located with standard acute-care hospitals that may face fewer barriers for transferring patients. Further, we find that facilities operated by the two dominant LTCH chains are more likely to strategically discharge patients — and when these chains acquire competing facilities, the newly acquired facilities become more likely to do so as well. Lastly, we show that the most vulnerable patients in this setting — the elderly and African Americans - are the most susceptible to strategic discharge.

Although our descriptive analysis provides compelling evidence that LTCHs strategically discharge patients given the current PPS, it does not allow us to predict how LTCHs would behave under alternative payment schemes. Policy makers have a keen interest in making such predictions, however, as the costs of strategic discharge are potentially very large for Medicare perhaps as much as $\$ 2$ billion between 2007-2013 by some estimates (Weaver et al. 2/17/2015). In light of these costs, the Medicare Payment Advisory Commission (MedPAC) proposed a new formula in 2014 that would eliminate the large jump in reimbursements associated with crossing the SSO threshold, making strategic discharges less lucrative for LTCHs. In light of this proposal, we develop and estimate a dynamic structural model of LTCHs' discharge decisions that can predict the likely impact of such policy changes.

Conceptually, our model is based on an LTCH deciding each day whether to discharge a patient immediately or to keep her in the facility for an additional day. In making its decision, the LTCH weighs the revenue-based incentives of discharging the patient against the numerous 
cost-based and non-pecuniary reasons to keep the patient longer (e.g., the costs of treatment, the risk incurred by releasing the patient too early, the disutility of providing unnecessary treatments, and the marginal benefit of treatment to the patient). Here we exploit the nonlinear reimbursement schedule that generates a sharp jump in payments on the magic day and enables us to separately identify the revenue-based motives underlying facilities' discharge decisions from other confounding factors.

Using our estimated model, we find that LTCHs would discharge patients about a week earlier, on average, if they did not face the financial incentives of the current PPS, which would result in substantial cost savings for Medicare - over $\$ 500$ million per year across the nine most common DRGs that make up one-quarter of LTCH stays. We also find that for-profit hospitals and LTCHs housed within acute-care hospitals respond more strongly to financial incentives, and that these incentives have a larger effect on the discharge decisions for black and elderly patients.

The parameters we estimate in our structural model allow us to perform a counterfactual analysis of alternative payment policies. Of particular interest, we consider the new payment formula proposed by MedPAC that would eliminate the large lump-sum payments, replacing them with higher per-diem payments before the threshold. Under this system, patients are more likely to be discharged in the days prior to what would have been the SSO threshold because LTCHs no longer have an incentive to extend stays to secure a lump-sum payment on the magic day. At the same time, the larger per-diem payments themselves may provide an increased incentive to delay discharges. Based on our findings, the proposed formula would reduce the average stay by about a day relative to the status quo. This provides more modest savings than the previous counterfactual, on the order of about $\$ 19$ million each year for the nine most common DRGs.

Finally, we consider a more basic cost-plus reimbursement scheme in which LTCHs receive a fixed five percent mark-up over their reported costs. We find that, although it would eliminate the spike in discharges associated with the current PPS, hospitals would hold patients longer than they do under the status quo because they profit from receiving a constant mark-up. This underscores the challenges involved with adequately reimbursing LTCHs while also taking into account the strategic incentives generated by such payment policies.

One limitation of a counterfactual analysis that focuses solely on the monetary costs associated with a patient's length of stay is that patients may benefit from being kept in the hospital while LTCHs try to reach the magic day, leaving the overall welfare effect of the policy indeterminate. We provide two pieces of evidence that suggest these extra days spent in the LTCH do not provide meaningful health benefits - if anything, they appear to harm patients. Using the SSO threshold as an instrument that exogenously shifts a patient's length of stay, we first show that an extra day in the LTCH substantially increases the risk of inpatient mortality and readmission to an acute-care hospital. Similarly, extra days in the LTCH increase the likelihood of negative 
outcomes such as developing bed sores or contracting infections. Because these adverse events further increase medical costs and unambiguously harm patients, we view our counterfactual estimates of the cost savings from alternative reimbursement schemes as conservative lower bounds for the total savings that Medicare might achieve.

These results contribute to several streams of literature. First, we add to existing work on the incentives to reduce health-care expenditures that to this point has focused primarily on patients (e.g., responding to cost-sharing in their insurance plans ${ }^{4}$ ) or on physicians (e.g., on where to admit patient: 5 . By showing how inpatient hospitals respond to incentives to reduce expenditures, our paper offers an important contribution to this growing literature. In related and ongoing work, developed independently from our own, Einav et al. (2016) also look at the discharge practices of LTCHs and report similar findings.

Our paper also contributes to that on the unintended consequences of Medicare reimbursement policies (e.g., Altman 2012, Decarolis 2015, Dafny 2005). Most directly related to our work, Kim et al. (2015) document several stylized facts for LTCHs following Medicare's change to a PPS in 2002, including a spike in discharges immediately after the SSO threshold. We extend these results by considering a broader set of DRGs, incorporating the health outcomes of patients, and estimating a structural model of LTCH behavior that allows for counterfactual policy analysis. In addition, we explicitly outline an identification strategy for uncovering strategic behavior by LTCHs, as well as establish several novel institutional nuances, such as the post-acquisition discharge policies of Kindred and Select's LTCHs, the behavior of co-located LTCHs, and the different treatment of elderly and African-American patients.

We also provide new evidence related to the extensive literature on for-profit healthcare providers (e.g., Schlesinger \& Gray 2006, Dranove 1988, Chakravarty et al. 2006, Wilson 2013). In showing that for-profit LTCHs seek to maximize reimbursements from Medicare more often than non-profits do, we bolster similar findings in this vein, such as those in Silverman \& Skinner (2004). Others, such as Grieco \& McDevitt (forthcoming), have found that for-profit health-care providers often deliver lower-quality care. This may also be the case for LTCHs given previous reports, such as Berenson (2/9/2010) who finds that LTCHs have been cited at a rate almost four times that of regular acute-care hospitals for serious violations of Medicare rules and have had a much higher incidence of infections and bedsores. Our findings add to this literature by showing that patient outcomes are negatively affected by the financial incentives LTCHs face to hold patients until the magic day.

The remainder of our paper continues in Section 2, which provides background details on LTCHs. Section 3 discusses the data. Section 4 provides descriptive evidence of strategic discharging by LTCHs. Section 5 shows how unnecessary days spent in an LTCH harm patients.

\footnotetext{
${ }^{4}$ See, for example, Manning et al. (1987), Newhouse (1993), or Einav et al. (2013).

${ }^{5}$ See, for example, Ho \& Pakes (2014).
} 
Section 6 describes our structural model of LTCH discharge decisions. Section 7 presents our estimates of this model and shows our counterfactual analysis of Medicare's proposed reimbursement plan, along with two other schemes. Section 8 concludes. The online appendices contain robustness checks of our main results for several DRGs, summary statistics for LTCHs across all DRGs, a thorough example of the exact calculations used to compute reimbursements for LTCHs, and several figures relevant for our counterfactual analysis.

\section{Overview of Long-term Care Hospitals}

Long-term care hospitals provide inpatient care for patients with prolonged, post-acute medical needs. To qualify as an LTCH, a facility must meet Medicare's qualifications for being a general acute-care hospital and also have an average length of stay greater than 25 days for its Medicare patients. As an organizational form, LTCHs were established in the 1980s during Medicare's transition to a PPS, under which general acute-care hospitals began to receive a set payment for each treatment rather than one based on their direct costs. CMS exempted hospitals with long average lengths of stay from the new PPS due to concerns that they would not be financially viable under this system. In 2002, Medicare then further adjusted the LTCH reimbursement scheme to what is now its current form, which we discuss in greater detail below.

Over the past three decades, LTCHs have been the fastest growing segment of Medicare's postacute care program (Kim et al. 2015). From fewer than 10 such facilities in the 1980s, the number of Medicare-certified LTCHs in the U.S. has now grown to more than 420, with payments from Medicare accounting for about two-thirds of overall revenue and totaling $\$ 5.5$ billion (Medicare

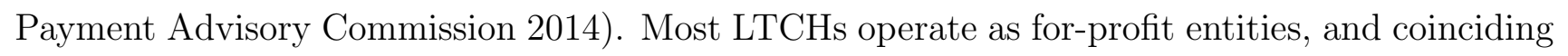
with industry growth, the market has consolidated to the point where two leading firms, Kindred Healthcare (Kindred) and Select Medical (Select), now operate 38 percent of all LTCHs, having expanded largely through acquisitions.

LTCHs receive payments from both patients and their insurers. For Medicare patients, who are the focus of our study, those transferred to an LTCH from an acute-care hospital do not pay an additional deductible, whereas those admitted from the community do pay one $(\$ 1,216$ in 2014) unless they have been discharged from a hospital within the last 60 days. In either case, an additional copayment is charged if the beneficiary stays longer than 60 days (a rare event occurring in only $4.7 \%$ of all LTCH stays from 2004-2013).6 Patients' payments are a small portion of the total payment received by LTCHs, however; even for a patient admitted from the community who pays a deductible and stays for 75 days in an LTCH (a very rare event occurring in just $0.17 \%$ of all LTCH stays from 2004-2013), the payment received from Medicare may be

\footnotetext{
${ }^{6}$ This was $\$ 304$ per day between 61 and 90 days. Beyond 90 days the patient has a lifetime reserve of 60 days covered by Medicare where the copay was $\$ 608$ in 2014 .
} 
ten times greater than the payment received from the patient. For more typical cases where the patient is transferred from an acute-care facility (and so pays no deductible) and stays for less than 60 days, Medicare is the sole source of revenue for the LTCH.

Before 2002, Medicare paid LTCHs for care based on their average cost per discharge. After 2002, Medicare began paying for LTCH care with a PPS intended to cover all of the operating and capital costs of treatment, which we detail in Online Appendix C. The LTCH PPS uses the same DRG groups as the acute inpatient PPS, but accounts for differences in the costs of treating regular inpatient cases and long-term care cases because the afflictions of patients requiring longer stays are typically more severe and more costly to treat. For this reason, full LTCH payments are usually much larger than Medicare payments for similar patients being treated in other types of facilities, such as the inpatient prospective payments (IPPS) received by general acute-care hospitals. As an example, DRG 207, respiratory system diagnosis with prolonged mechanical ventilation, had a standard IPPS payment of $\$ 30,480$ in 2014 compared to an LTCH payment of $\$ 80,098.7$

To discourage needless transfers between facilities and to ensure that only those patients who truly require long-term care are admitted to LTCHs, the full LTCH prospective payment is only paid for episodes of treatment lasting longer that five-sixths of the geometric mean of the length of stay for each DRG. Shorter stays are reimbursed as short-stay outliers, which are intentionally set to be much smaller than the full long-term care payments, and closer to the IPPS amount paid to acute-care hospitals for similar services. 8

Under Medicare's modified PPS, LTCHs receive payments that increase linearly with a patient's length of stay for short-stay outliers before culminating in a discrete jump in reimbursements on the magic day. The nonlinearities in Medicare's reimbursement of LTCHs thus create a strong financial incentive to keep patients just beyond the SSO threshold. As an example, consider Figure 1 that shows for DRG 207 the estimated average costs (dashed line) and the average Medicare payments (solid line) broken down by length of stay in 2013, with the gray bands indicating the 25th and 75th percentiles. $9^{9}$ In this year, the SSO threshold was 26.7 days, and the jump in payments just beyond this point is immediately evident.

The quotes from industry sources in the Introduction describe the type of pressure put on LTCH employees to maximize profits by keeping patients longer than medically necessary and then discharging them quickly after they pass the SSO threshold. Figure 11 clearly illustrates

\footnotetext{
${ }^{7}$ See Medicare Payment Advisory Commission (2014), chapter 11.

${ }^{8}$ See Online Appendix C for full details of this payment schedule and an example calculation.

${ }^{9}$ We use our claims data (introduced below) to estimate costs as covered charges $\times$ cost-to-charges ratio, which is the same formula used by CMS to estimate 100 percent of the cost of care for SSOs. The cost-to-charge ratio (CCR) is calculated for each hospital based on their annual cost reports as the overall ratio of total costs to total covered charges. In reality, the CCR likely varies by patient within a hospital. For example, sicker patients who stay longer are probably more expensive and have higher CCRs than less-sick patients within the same DRG. In this case, the cost estimate is biased upward for the shorter stays and downward for the longer stays.
} 


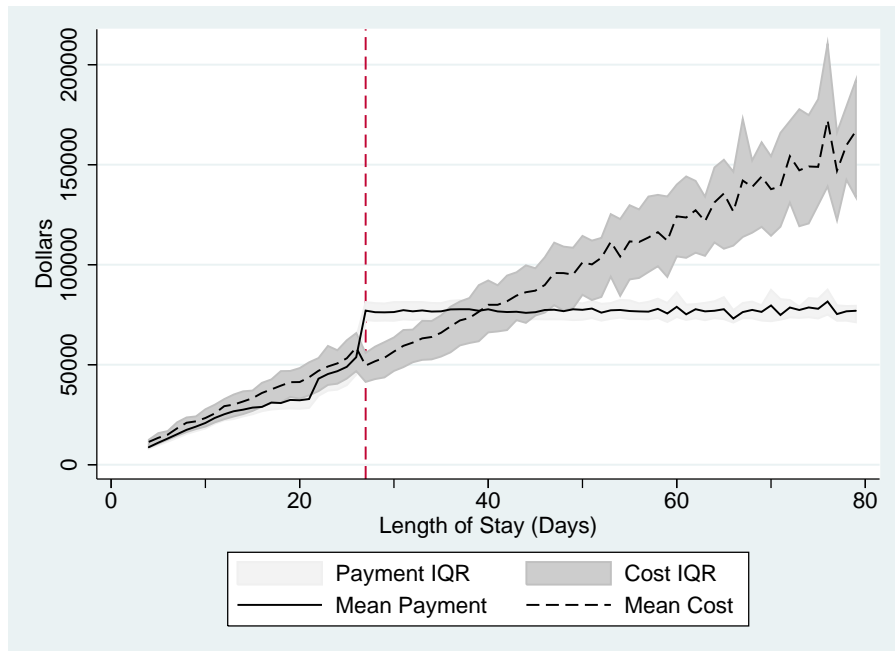

Figure 1: Revenues and Costs for DRG 207 Patients by Length of Stay, FY 2013

the source of this pressure for DRG 207: the average payment on day 26 is $\$ 53,762.53$, but then jumps to $\$ 77,049.16$ just one day later. If we impute daily costs from hospital charges and costto-charge ratios (see footnote 9), this corresponds to the average profit per patient jumping from $\$-4,332.62$ on the day before the SSO threshold to $\$ 27,508.59$ on the magic day. After reaching the SSO threshold, the LTCH receives no further payments for the patient, so profits begin to fall as the hospital continues to incur costs during treatment. In the case of DRG 207, Figure 1 shows that additional costs completely exhaust profits after day 40, leading to a roughly 2 week window of profitability for the hospital. In 2013, 45 percent of discharges occurred within that window compared to only 5 percent in 2002, the year before the current PPS was introduced

Another distinguishing feature of the LTCH market is that nearly one-third operate within general acute-care hospitals, so-called hospital-within-hospitals (HwH). Although co-located, both the LTCH and general acute-care hospital are organizationally, managerially, and financially independent. Such an arrangement yields some efficiencies, as it allows for the sharing of costs like laboratories and cleaning services. More controversially, this arrangement also makes it easier to transfer patients between the co-located hospitals, by which both hospitals stand to gain: a transfer allows the LTCH to receive a separate payment from Medicare, while the acute-care hospital frees up a bed for a new patient with a new reimbursement. As noted in Kahn et al. (2015), a patient in an acute-care general hospital co-located with an LTCH is much more likely to be transferred to an LTCH, with patients potentially selected based on factors other than clinical appropriateness. Because LTCHs do not operate emergency rooms, they have considerable discretion over which patients to admit, and such behavior has prompted plans from Medicare to reduce payments to LTCHs that receive more than 25 percent of their patients from a single hospital.10

\footnotetext{
${ }^{10}$ To discourage LTCHs as being treated as though they were extensions of short-term acute-care hospitals,
} 


\section{Data Description and Motivating Facts}

For our analysis, we use a claims dataset from CMS linked to data on hospital characteristics from CMS and the American Hospital Association. The claims data come from the de-identified Limited Data Set (LDS) version of the Long-Term Care Hospital PPS Expanded Modified MEDPAR file, which contains records for 100 percent of Medicare beneficiaries' stays at long-term acute care hospitals 11 Our particular data are limited to long-term stays for fiscal years 2002, when the old reimbursement system was still in effect, and 2004 through 2013.12 The data include the billed DRG, Medicare payments, covered costs, length of stay, diagnosis and procedural codes, race, age, gender, the type of hospital admission, whether the patient was discharged alive, and, if so, the discharge destination (i.e., discharge to home care, to a general hospital, etc). The CMS certification number of the hospitals allows us to link the claims data to data on hospital characteristics, although the de-identification of patients means we cannot measure some patient-level outcomes, such as readmissions.

The hospital data come from two sources, the American Hospital Association (AHA) Guide and Medicare's Provider of Services (POS) files ${ }^{13}$ The POS files contain data on hospital characteristics including name, location, hospital type, size, for-profit status, medical school affiliation, services offered, and the hospital's CMS certification number. Because hospitals are added to the POS file when they are certified as Medicare and Medicaid providers, in principle one could use historical versions of these reports to construct a panel dataset of all eligible providers. Once a hospital becomes a part of the POS file, however, CMS regional offices only intermittently administer surveys and update the dataset, meaning that we may not observe precisely when time-varying hospital characteristics actually change. As ownership, and the timing of ownership changes, are of particular interest to us, we address this issue by supplementing the POS data with data from the AHA Guide.

The AHA administers an annual survey of hospitals in the U.S. and uses them to compile a comprehensive hospital directory known as the AHA Guide. These guides contain various details about hospitals, such as their organizational structure, services provided, and bed count. We used hard copies of the guide to record data on hospital ownership changes for LTCHs and then linked this to the POS data to improve the data for ownership and ownership changes. In

Medicare stipulated in 2005 that if more than 25 percent of the LTCH's discharges were admitted from its colocated hospital, then the net payment amount for those discharges beyond the 25 percent mark became the lesser of the LTC-DRG or the amount Medicare would have paid under IPPS. In 2007, it was expanded to include all LTCH hospitals and the 25 percent threshold was raised for some hospitals to as much as 75 percent. See Long Term Care Hospital Prospective Payment System: Payment System Fact Sheet Series. The Medicare Learning Network. December 2014.

${ }^{11}$ For further information, please see https://www.cms.gov/Research-Statistics-Data-and-Systems/ Files-for-Order/LimitedDataSets/LTCHPPSMEDPAR.html.

${ }^{12}$ CMS has not made 2003 data available to researchers.

${ }^{13}$ See https://www.cms.gov/Research-Statistics-Data-and-Systems/Downloadable-Public-Use-Files/ Provider-of-Services/index.html. 
addition, we collected hospital system affiliation and co-location data from the AHA Guide. We classify LTCHs listed in the AHA Guide as being located within another hospital as hospitalswithin-hospitals.

Much of our analysis focuses on hospital stays coded as DRG 207 for patients ultimately discharged to home care or nursing facilities. We focus on DRG 207 because it is the most common DRG and also the most highly reimbursed, although we extend our analysis to the other eight most common DRGs in the appendices to highlight the robustness of our results. ${ }^{14}$ Our complete dataset contains records for 1.45 million long-term hospital stays between 2004 and 2013 classified into as many as 751 DRGs 15 Of these, 170,365 are classified as DRG 207, with 90,755 terminating in a discharge to home or a nursing facility.

Table 1 contains summary statistics for these 90,755 stays ${ }^{16}$ For this sample, the mean length of stay is 42.43 days and 87 percent of patients stay until the SSO threshold. The average total payment to hospitals is $\$ 71,108$; most of this, $\$ 70,530$, comes from Medicare, with the rest paid as a deductible, as co-insurance, or by a third party. Age, race, gender, and ethnicity are also summarized in the table. About 25 percent of these patients are under age 65, the age of universal Medicare coverage, because they qualified for Medicare in other ways, such as by receiving Social Security Disability Insurance or by having end-stage renal disease.

Table 2 contains summary statistics for our sample of LTCHs, with the bottom panel displaying summary statistics weighted by hospital size (bed count). As mentioned above, the largest two firms are Kindred and Select, which together operate almost 40 percent of facilities. Nearly one-third of LTCHs are HwH. For-profits comprise two-thirds of LTCHs, while government-owned LTCHs make up 7 percent of the sample but contain 16.6 percent of total beds; just under 10 percent of LTCHs are affiliated with medical schools. Across all types, LTCHS have an average bed count of 70 .

\section{Evidence of Strategic Discharging}

In this section, we provide evidence that the financial incentives created by Medicare's PPS influence LTCHs' discharge decisions. The crux of our analysis is that the discontinuous jump in payments at the SSO threshold (e.g., Figure 1) corresponds to a discontinuous jump in discharges. To establish that the discontinuity in payments causes the discontinuity in discharges, we exploit several institutional details for identification: (i) variation in the SSO threshold across years

\footnotetext{
${ }^{14}$ Below we will also leverage the data from all nine of these DRGs in two additional ways. First, we will use the variation in the size of the magic day payment to show that patients with DRGs where the jump in payment is greatest are most likely to be strategically discharged. Second, we will use data from all nine DRGs when we estimate our structural model.

${ }^{15}$ We omit data from 2002 as the PPS policy does not apply.

${ }^{16}$ See Online Appendix A for complete summary statistics for all LTCH episodes of hospitalization, for all stays coded to DRG 207, and for the other eight DRGs that we focus on.
} 
Table 1: Summary Statistics for Patients Discharged to Home or Nursing Facility Care with DRG 207 (2004-2013)

\begin{tabular}{|c|c|c|}
\hline Variable & Mean & Std. Dev. \\
\hline Length of Stay & 42.425 & 24.062 \\
\hline Released After SSO Threshold & 0.867 & 0.34 \\
\hline Total Payment ${ }^{1}(\$)$ & $71,107.908$ & $23,259.546$ \\
\hline Amount Paid by Medicare $(\$)$ & $70,530.388$ & $28,385.701$ \\
\hline Estimated Costs $(\$)$ & $74,390.038$ & $47,003.876$ \\
\hline Portion Discharged to Home Care & 0.234 & 0.424 \\
\hline Portion Discharged to Nursing Facility & 0.766 & 0.423 \\
\hline Male & 0.484 & 0.5 \\
\hline White & 0.746 & 0.435 \\
\hline Black & 0.191 & 0.393 \\
\hline Asian & 0.014 & 0.119 \\
\hline Hispanic & 0.024 & 0.154 \\
\hline Age less than 25 & 0.002 & 0.043 \\
\hline Age between 25 and 44 & 0.038 & 0.192 \\
\hline Age between 45 and 64 & 0.218 & 0.413 \\
\hline Age between 65 and 74 & 0.361 & 0.48 \\
\hline Age bewteen 75 and 84 & 0.291 & 0.454 \\
\hline Age over 85 & 0.089 & 0.285 \\
\hline \multicolumn{3}{|l|}{$N=90,755$} \\
\hline \multicolumn{3}{|c|}{$\begin{array}{l}1 \text { Some observations were omitted because they reported Medi- } \\
\text { care payments of } \$ 0 \text {. The majority of these are believed to be re- } \\
\text { admissions that did not quality for additional Medicare payments. } \\
\text { Limitations in our data do not allow us to link these to their initial } \\
\text { admission so we drop them. }\end{array}$} \\
\hline
\end{tabular}

within the same DRG, (ii) variation in the SSO threshold across DRGs within the same year, (iii) variation in the presence of the SSO threshold given Medicare's policy change in 2002, (iv) variation in the size of the payment discontinuity at the SSO threshold across DRGs, (v) variation in the ease of manipulating discharges across discharge destinations, and (vi) variation in the incentives faced by different types of hospitals to engage in strategic discharge (e.g., for-profit vs. non-profit). The central message that emerges from these different sources of variation is a clear one: the observed discharge patterns in the data stem from deliberate choices made by LTCHs in response to Medicare's PPS rather than a coincidental improvement in patients' health that occurs right after they pass the SSO threshold. In Section 4.1, we use histograms to provide visual evidence in support of our arguments. In Section 4.2, we quantify the extent of strategic discharging in a difference-in-difference regression that exploits variation in the SSO discontinuity across DRGs and over time. 
Table 2: Summary Statistics for LTCHs (2004-2013)

\begin{tabular}{lcc}
\hline Variable & Mean & Std. Dev. \\
\hline Kindred Healthcare & 0.158 & 0.365 \\
Select Medical & 0.203 & 0.402 \\
Hospital within hospital & 0.328 & 0.470 \\
For-profit & 0.657 & 0.475 \\
Non-profit & 0.274 & 0.446 \\
Government owned & 0.069 & 0.254 \\
Bed count & 69.66 & 87.49 \\
Affiliated with medical school & 0.091 & 0.287 \\
\hline \multicolumn{2}{c}{ Weighted by bed count } \\
\hline Kindred Healthcare & 0.199 & 0.399 \\
Select Medical & 0.131 & 0.337 \\
Hospital within hospital & 0.187 & 0.39 \\
For-profit & 0.559 & 0.496 \\
Non-profit & 0.275 & 0.446 \\
Government owned & 0.166 & 0.372 \\
Affiliated with medical school & 0.180 & 0.384 \\
\hline$N=4,108$ & \\
\hline
\end{tabular}

\subsection{Graphical Evidence}

We first examine the distribution of discharges to home or a nursing facility for a single DRG, DRG 207, relative to its SSO threshold. The discontinuity in discharges at the SSO threshold is immediately apparent in Figure 2, which shows a marked spike on the magic day along with a pronounced dip for the days immediately preceding it ${ }^{17}$ Typically, one would expect a smooth distribution of discharges absent any deliberate manipulation by LTCHs; the spike in discharges on the days immediately after the SSO threshold suggests that LTCHs base their decisions on factors other than just clinical guidelines.

Given that Medicare sets the SSO threshold based on specific criteria, however, we cannot rule out the possibility that the underlying treatment regimen for DRG 207 just happens to naturally result in a mass of discharges on that day. To link the spike in discharges to facilities' financial incentives, we will therefore use several sources of variation in the data to identify a consistent pattern of strategic behavior, starting in this subsection with a series of suggestive histograms. We also supplement these charts with Table A3 in the online appendix that summarizes key statistics from the histograms, such as the percentage of patients discharged on the magic day, which we refer to often throughout our discussion.

\footnotetext{
${ }^{17}$ The $\mathrm{x}$-axis in Figure 2 has been normalized to show the day of discharge relative to the magic day, as the magic day changes over time.
} 


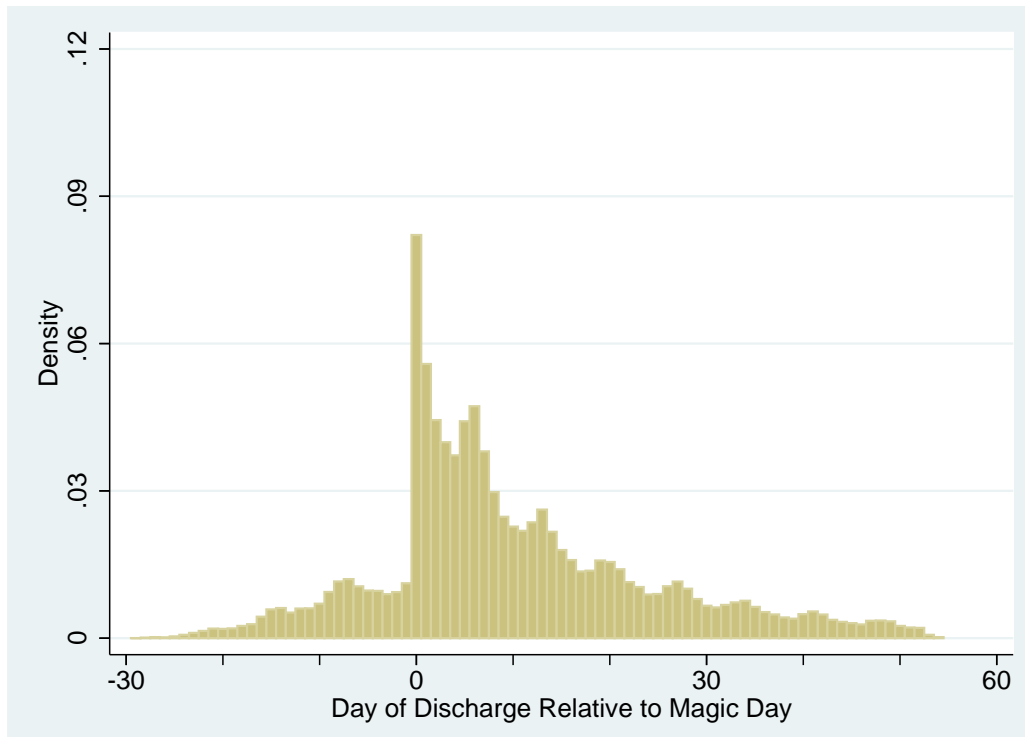

Figure 2: Distribution of Length of Stay Relative to Magic Day, FY 2004-2013

For our first source of identifying variation, we show how the distribution of patients' lengths of stay has evolved over time. Figure 3 presents the distributions for 2002, 2004 and 2013, where the dashed vertical line denotes the magic day in 2013, the 27th day, and the solid vertical line denotes the magic day in 2004, the 30th day. In panel (a), we see that in 2002, when Medicare's reimbursement schedule did not include a lump-sum payment, there is no discernible spike in discharges. After implementing the LTCH PPS, however, a distinct spike emerges on the magic day in panel (b) for 2004 and panel (c) for 2013. In 2004, 2.1 percent of patients were discharged on the day right before the magic day compared to 4.6 percent on the magic day, a 2.2-fold increase. In 2013, by contrast, 1.4 percent of patients were discharged on the day right before the magic day compared to 10.2 percent on the magic day, a substantially larger 7.3-fold increase.

In comparing panel (a) with panels (b) and (c), it is clear that when there is no discontinuity in the reimbursement scheme, there is also no spike in discharges around what would subsequently become magic days. In addition, comparing panels (b) and (c), we see that in 2004 the spike in discharges occurs on day 30, the magic day for that year, while in 2013 this spike occurs on day 27, the magic day for that year 18 Although theoretically possible, it is unlikely that medical advances caused this shift. Rather, the more likely reason that discharges spike earlier in 2013 is that this is when LTCHs receive larger payments, and the lack of a similar spike in 2002 further bolsters this claim. Moreover, we show the same distinct pattern emerges across the other mostcommon DRGs in the online appendix (see Figure A1 in Online Appendix B). It is even more unlikely that several independent medical advances occurred for each of these different DRGs in

\footnotetext{
${ }^{18}$ We also note the increase between 2004 and 2013 in the ratio of patients released on the magic day relative to the preceding day. We are currently exploring this pattern in ongoing work and view an explanation of this trend, such as a gradual rollout of the PPS or LTCHs learning how to best maximize profits, as interesting but beyond the scope of our current paper.
} 


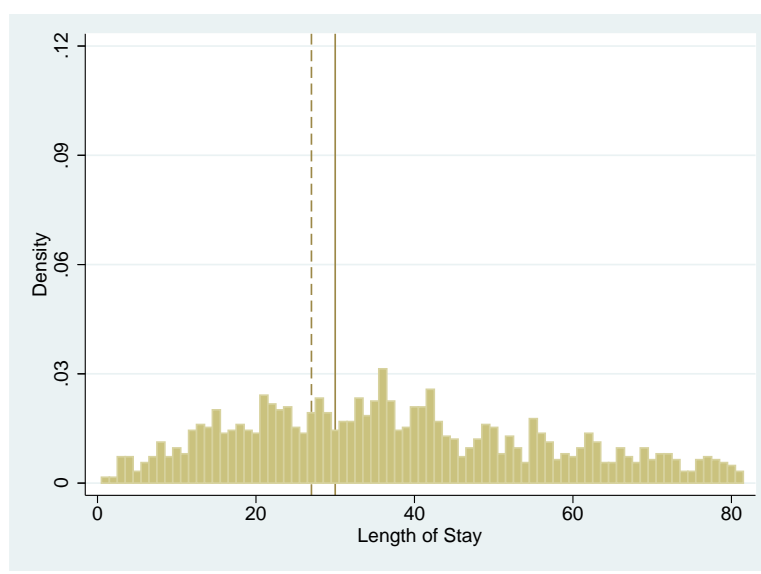

(a) Absolute Length of Stay, FY 2002

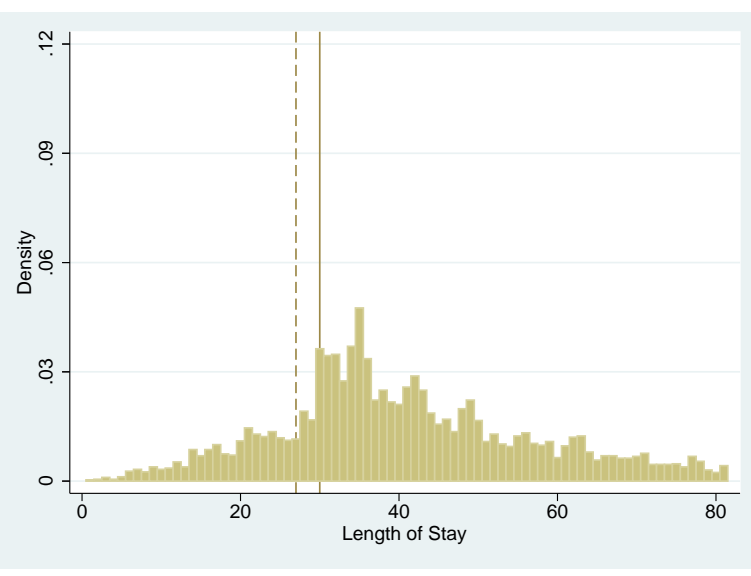

(b) Absolute Length of Stay, FY 2004

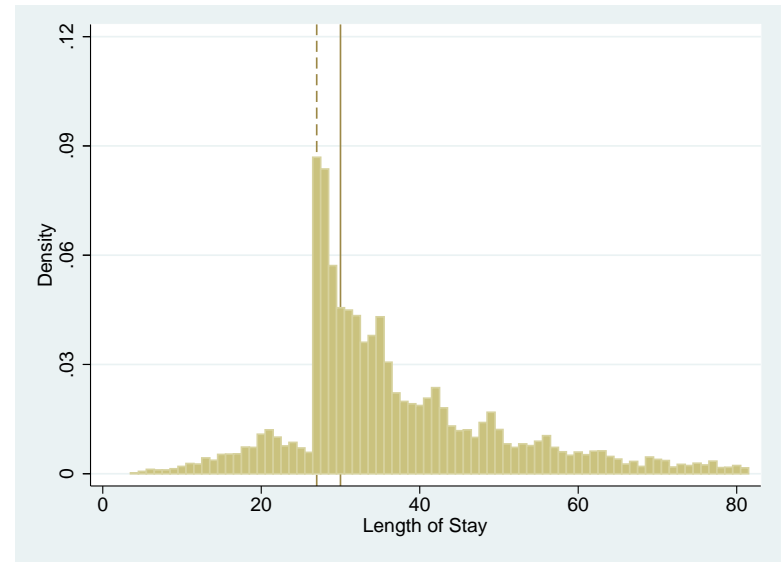

(c) Absolute Length of Stay, FY 2013

Figure 3: Discharge patterns for DRG 207. Solid vertical line is SSO threshold in 2004. Dashed vertical line is SSO threshold in 2013.

a way that coincidentally shifted discharges to precisely after their DRGs' SSO thresholds 19

For our second source of variation, we look at differences in discharge patterns by destination, categorized by how easily an LTCH could alter a patient's treatment plan based on financial incentives. Discharges to home are the easiest type for LTCHs to manipulate because they have the least subsequent oversight and these patients' conditions have stabilized enough so that they can be sent home. Discharges to skilled nursing facilities are slightly more difficult to exploit because trained medical staff evaluate a patient following the transfer and these patients still have many lingering health issues. Discharges to acute-care hospitals will then be even harder to manipulate because they have more extensive admission screening and these patients have a comparatively worse health status. Finally, discharges due to death will be extremely hard to manipulate (for obvious reasons). In Figure 4 , we show that discharge patterns exactly line

\footnotetext{
${ }^{19}$ In Section 4.2 , we relate the likelihood of strategically discharging a patient to that patient's DRG's lump-sum payment to build the argument that strategic discharges are most likely for those DRGs where the discontinuity is greatest.
} 
up with this hypothesis. The spike is most pronounced for discharges to home and least for discharges due to death, which has no bump at all on the magic day. For patients discharged to home, LTCHs discharge 6.1 times as many patients on the magic day relative to the day before it, whereas for patients discharged due to death the corresponding ratio is a flat 1.0.

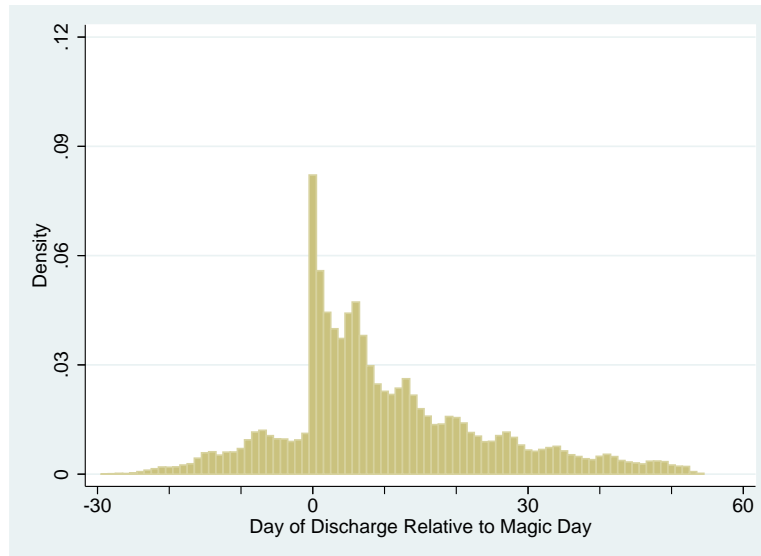

(a) Home

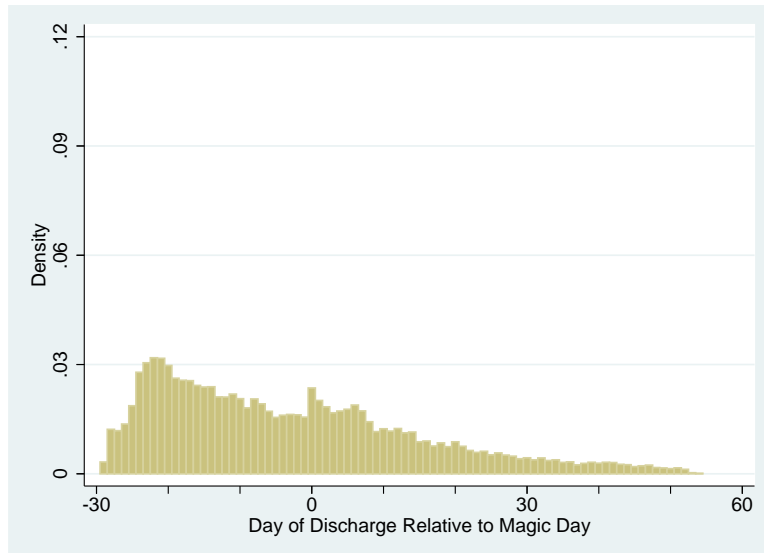

(c) Acute-care Hospital

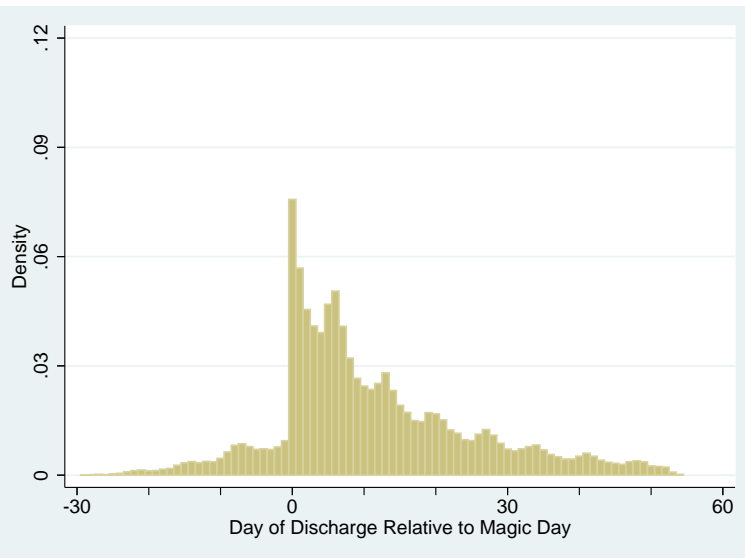

(b) Skilled Nursing Facility

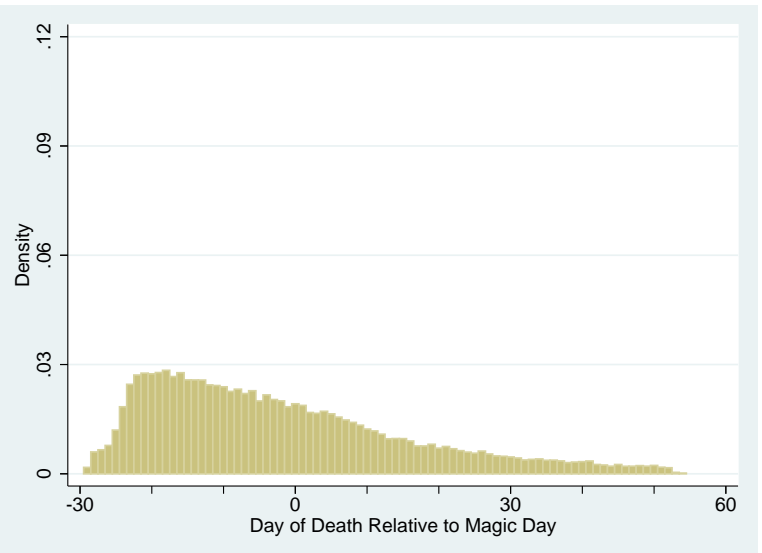

(d) Death

Figure 4: Discharge Patterns for DRG 207 by Destination, FY 2004-2013

For our final source of variation, we consider how discharge patterns vary based on several different categorizations of LTCHs. Across the three types we consider, LTCHs facing the strongest financial incentives to strategically discharge patients are consistently more likely to do so. First, for-profit LTCHs presumably have a stronger incentive to engage in strategic discharge because they have an explicit mandate to maximize profits. In keeping with this motivation, Figure 5 shows that for-profits discharge 9.2 times as many patients on the magic day compared to the day before it, whereas non-profit LTCHs have a spike about half as large, at 4.6 times.

The second hospital type we consider is whether an LTCH is owned and operated by one of the two dominant chains, Kindred or Select. These chains have grown extensively over the past decade by acquiring existing LTCHs, as well as through greenfield investment. As maximizing reimbursements is a primary way to increase corporate earnings — and thus may be a 


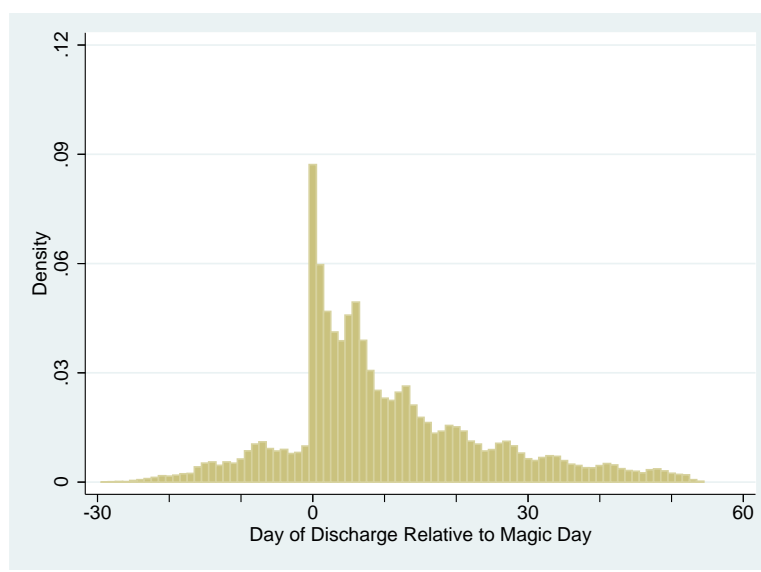

(a) For-Profit LTCHs

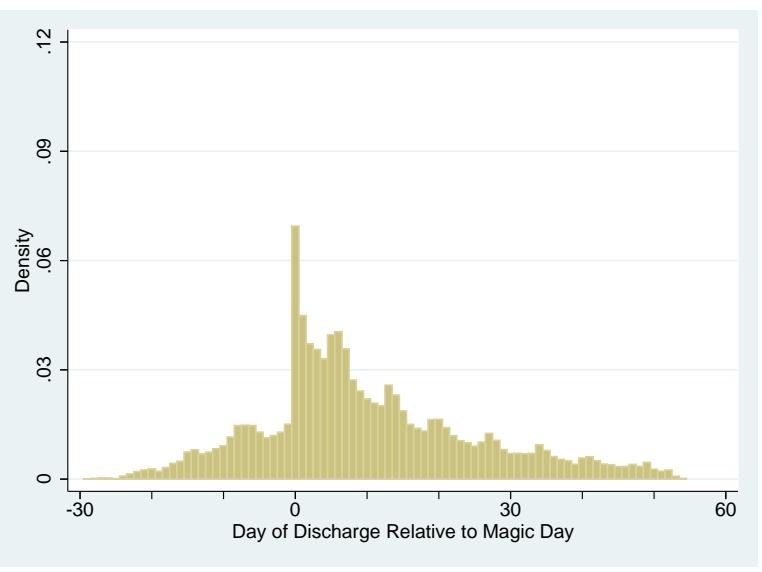

(b) Non-profit LTCHs

Figure 5: Discharge patterns for DRG 207 by LTCH Profit Type, FY 2004-2013

central component of their growth strategies — it is possible that Kindred and Select acquire LTCHs specifically to implement their more-lucrative discharge policies. To this point, Berenson (2/9/2010) provides an example from 2007 where an inspector for Medicare found that "a case manager at a Select hospital in Kansas had refused to discharge a patient despite the wishes of her physician and family. The hospital calculated it would lose $\$ 3,853.52$ if it discharged the patient when the family wanted, the inspector found." The discharge patterns in Figure 6 are consistent with such a corporate strategy. When Kindred and Select acquire LTCHs, the ratio of discharges on the magic day relative to the day before it increases from 8.7 to 15.1, suggesting that the acquired LTCHs subsequently adopt their acquirers' discharge policies. ${ }^{20}$

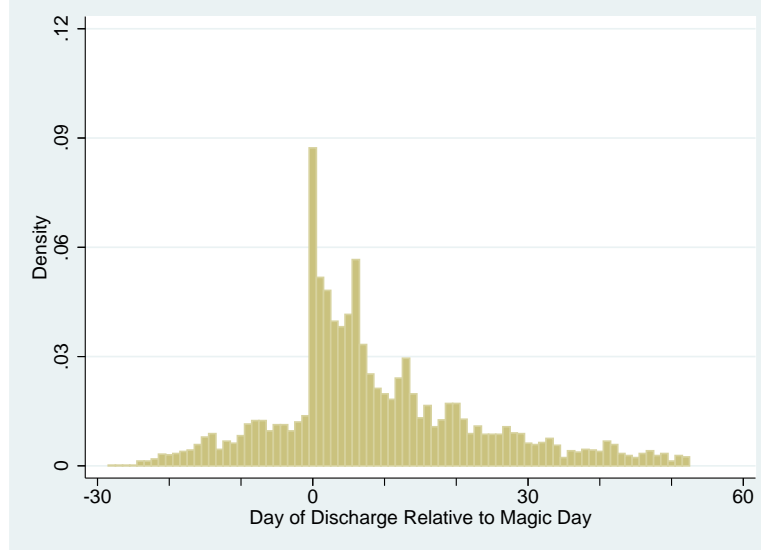

(a) Before Acquired by Select or Kindred

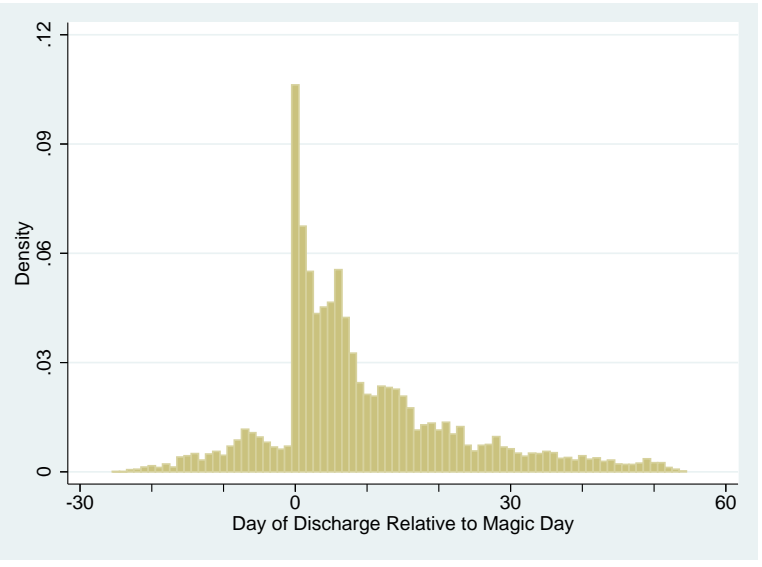

(b) After Acquired by Select or Kindred

Figure 6: Discharge patterns for DRG 207 Pre- and Post-Acquisition, FY 2004-2013

The final type of LTCH we consider is whether the LTCH operates within an acute-care

\footnotetext{
${ }^{20}$ We also show below that Kindred- and Select-operated LTCHs are more likely to strategically discharge patients; that is, overall their facilities are more likely to strategically discharge patients, and when they acquire a new facility, that facility is more likely to strategically discharge patients than it was before being acquired.
} 


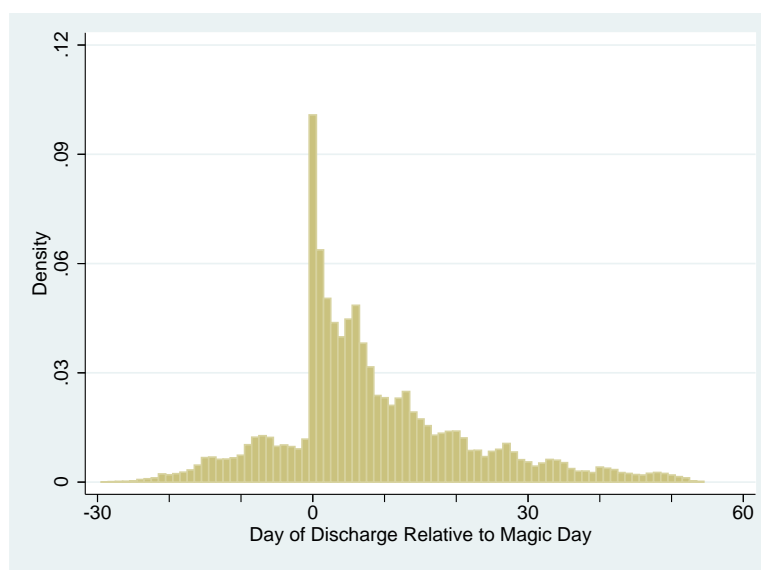

(a) Co-located LTCHs

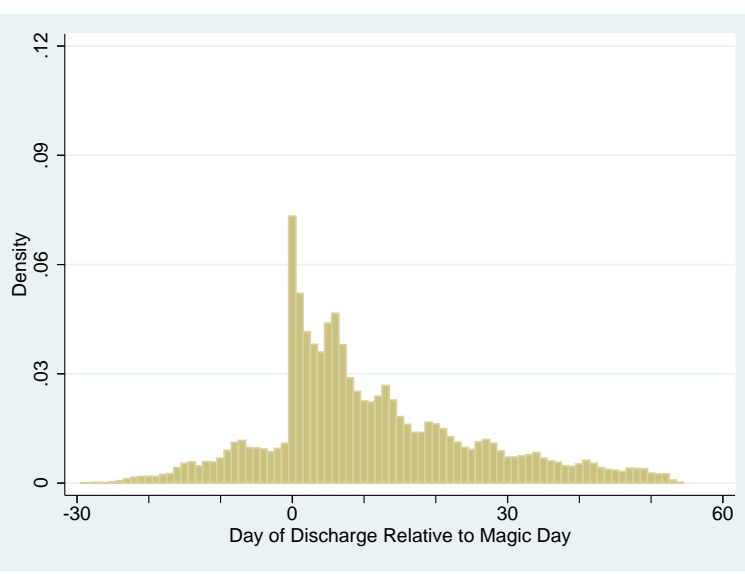

(b) Standalone LTCHs

Figure 7: Discharge patterns for DRG 207 by LTCH location type, FY 2004-2013

hospital, which we refer to as a HwH. Co-located LTCHs may face fewer barriers for manipulating discharges, and therefore we may see a larger spike in discharges on the magic day. Officially, hospitals have little control over such facilities and patients can choose where to go. In practice, however, hospital discharge teams often steer patients to a favored facility. Consistent with our expectations, Figure 7 shows a larger spike in discharges on the magic day for co-located LTCHs compared to standalone LTCHs, at 10.1 percent and 7.3 percent, respectively. Co-located LTCHs discharge 8.4 times as many patients on the magic day relative to the day before it, whereas standalone LTCHs discharge 6.6 times as many.

\subsection{Quantifying the SSO Threshold Effect}

The preceding figures provide strong visual evidence that discharges spike on the magic day, with the magnitude varying based on factors correlated with LTCHs' financial incentives. To quantify these patterns in a rigorous yet parsimonious way, Table 3 shows the results from a series of probit regressions that estimate the probability of discharge given a patient's length of stay in relation to her particular SSO threshold:

$$
\operatorname{Pr}(\text { discharge } \mid t, s)=\Phi\left(\gamma_{0}+\gamma_{1} t+\gamma_{2} t^{2}+\mu_{s}\right)
$$

where $t$ is the absolute day of the hospital stay and $s$ is the day relative to the magic day $(s=0$ indicates the day is the magic day, $s<0$ indicates days before the magic day, and $s>0$ indicates days after the threshold day). We present the results for DRG 207 in the main text and the analogous results for the next three most common DRGs in Online Appendix $B{ }^{21}$

This simple model relies on variation in the SSO threshold across years to identify the impact

\footnotetext{
${ }^{21}$ We estimate this regression separately for each DRG to isolate the strategic effect of discharge from any other differences that may exist across diagnoses.
} 
of the lump-sum payment on discharges, assuming that any time spent in an LTCH improves patients' health in a continuous manner — that is, patients' conditions improve smoothly over the course of a stay in contrast to the payments that jump discretely. We include a quadratic function of a patient's length of stay to capture the non-strategic impact of time spent in the hospital on the probability of discharge, while the relative days capture the strategic component. For example, one would expect the likelihood of being discharged for clinical reasons on, say, the 25 th day not to vary much within a DRG across years. But, if the 25th day happens to be the magic day in one year but the 26th day in another, the year in which it coincides with the magic day should have a greater likelihood of discharge if LTCHs are acting strategically to maximize reimbursements. In the regressions, $\mu_{s}$ captures this strategic behavior.

Table 3 presents the estimated discharge probabilities from this model for DRG 207. ${ }^{22}$ The sample we use here is based on stays that ended in a discharge to home care or a nursing facility since these are the discharges for which hospitals have the most discretion. In all cases, we see a sharp jump in discharges on the magic day relative to the day before, and this pattern is remarkably consistent across years. For instance, in 2010 when the SSO threshold was 29 days, the probability of discharge increases from 1.11 percent on the day before the magic day to 8.86 percent on the day of the threshold, a nearly eightfold increase. In 2013, when the threshold day was two days earlier, on day 27, the rate increased from 1.3 percent to 9.7 percent, a similar order of magnitude as in 2010.

Given the finding above that financial incentives influence the timing of LTCHs' discharges, we would expect this response to vary based on the amount of potential profit at stake. To this point, we show in Online Appendix B that among the four most common DRGs, the magic day effect is strongest in DRG 207, which has the highest payment/cost ratio on the magic day. For DRG 207, profits increase approximately $\$ 30,000$ by discharging on the magic day compared to the day before, and the median magic day effect across all years in our data is 7.96. By contrast, DRG 189 and DRG 871 have smaller payment bumps of $\$ 12,000$ and $\$ 11,000$, respectively, that correspond to likewise similar and smaller median magic day effects of 6.29 and 6.55. Finally, DRG 177 has an even smaller payment bump of $\$ 9,000$ to go along with its smaller median magic day effect of 3.77 .

In addition, different types of LTCHs may respond more strongly to financial incentives. To see this, we next interact the SSO threshold effects with various LTCH characteristics, which allows discharge practices to vary by hospital type. The estimating equation for these models has the form

$$
\operatorname{Pr}(\text { discharge|t, } s, i)=\Phi\left(\gamma_{0}+\gamma_{1} t+\gamma_{2} t^{2}+\mu_{s, x(i)}\right)
$$

where $x(i)$ is an indicator variable for whether observation $i$ is of type $x$, such as whether it

\footnotetext{
${ }^{22}$ The parameter estimates for the probit model appear in Table A9 in Online Appendix D for DRG 207. Estimates for other DRGs are available upon request.
} 
Table 3: Marginal Effects on Probability of Discharge

DRG 207

\begin{tabular}{cccc}
\hline $\begin{array}{c}\text { Day of } \\
\text { stay }(t)\end{array}$ & $\begin{array}{c}\text { Probability of Discharge } \\
\text { on Magic Day }^{1}\end{array}$ & $\begin{array}{c}\text { Probability of Discharge } \\
\text { on Day Preceding Magic Day }\end{array}$ & $\begin{array}{c}\text { Hazard } \\
\text { Ratio }^{3}\end{array}$ \\
\hline 27 & $9.71^{* * *}$ & $1.27^{* * *}$ & $7.63^{* * *}$ \\
& $(0.337)$ & $(0.059)$ & {$[0.000]$} \\
28 & $9.27^{* * *}$ & $1.19^{* * *}$ & $7.80^{* * *}$ \\
& $(0.319)$ & $(0.057)$ & {$[0.000]$} \\
29 & $8.86^{* * *}$ & $1.11^{* * *}$ & $7.96^{* * *}$ \\
& $(0.320)$ & $(0.060)$ & {$[0.000]$} \\
30 & $8.48^{* * *}$ & $1.04^{* * *}$ & $8.12^{* * *}$ \\
& $(0.336)$ & $(0.064)$ & {$[0.000]$} \\
\hline
\end{tabular}

Note: Standard errors in parentheses. P-values in brackets. This sample contains only episodes of hospitalization that terminated in discharge to home care or nursing facilities. For results for other common DRGs, see Table A10

${ }^{1} \Phi\left(\gamma_{0}+\gamma_{1} t+\gamma_{2} t^{2}+\mu_{0}\right) * 100$

${ }^{2} \Phi\left(\gamma_{0}+\gamma_{1} t+\gamma_{2} t^{2}+\mu_{-1}\right) * 100$

${ }^{3}$ Hazard ratio: $\frac{\Phi\left(\gamma_{0}+\gamma_{1} t+\gamma_{2} t^{2}+\mu_{0}\right)}{\Phi\left(\gamma_{0}+\gamma_{1} t+\gamma_{2} t^{2}+\mu_{-1}\right)}$. Square brackets contain the p-value from a Wald test for $H_{0}: H R=\frac{\Phi\left(\gamma_{0}+\gamma_{1} t+\gamma_{2} t^{2}+\mu_{0}\right)}{\Phi\left(\gamma_{0}+\gamma_{1} t+\gamma_{2} t^{2}+\mu_{-1}\right)}=1$.

is a for-profit LTCH, a HwH, owned by Select of Kindred, or acquired by Select or Kindred. Using this model, the probability of discharge at hospital $i$ is a function of the absolute day of a stay, $t$, the relative day of a stay, $s$, and the hospital's characteristics. We limit the hospital characteristics to create a single partition of hospitals into types, as allowing for overlapping types would muddle the interpretation of the marginal effects.

Table 4 contains estimates for the marginal effects from six interacted probit models, with each model separated by a line in the table. We find that the magic day effect is nearly twice as large at for-profit LTCHs compared to non-profits, 9.60 relative to 4.99. For Kindred and Select, we estimate a magic day effect of 10.01, whereas it is only 6.12 for other LTCHs. Interestingly, just as Kindred and Select are more likely to strategically discharge patients than other hospitals in our second estimated model, in our third model individual LTCHs increase their strategic discharge behavior after being acquired by these chains from 6.70 to 16.82. Lastly, the magic day effect for co-located LTCHs is almost 30 percent higher than for standalone facilities, 9.42 compared to 7.34 .

We also investigate the prevalence of strategic discharge across patient types, as hospitals may treat patients differently if they have less influence over their own care. We examine two characteristics that may proxy for a patient's vulnerability in this regard, race and age. In the last panels of Table 4, we present results that include LTCH fixed effects to control for sorting of patients into hospitals and find that black patients are more likely to be strategically discharged 
than white patients: the magic day effect for black patients is nearly 30 percent larger ${ }^{23}$ In regards to age, however, we do not find evidence that the likelihood of strategic discharge is different for the elderly. In Section 7, we will return to this analysis in our structural model.

\section{The Effect of Longer Stays on Patient Outcomes}

Although our analysis above clearly shows that financial incentives influence LTCHs' discharge decisions and result in longer stays, the consequences of this behavior for patients are ex ante ambiguous. It is possible, for instance, that patients benefit from receiving extra care while the LTCH keeps them in the hospital to reach the SSO threshold. On the other hand, excess time spent in an LTCH may harm patients if they face a greater risk of experiencing adverse events, such as infections or bedsores. In our data, we have two pieces of evidence that suggest longer stays in an LTCH do not benefit patients. First, extra days in the LTCH increase the likelihood of contracting hospital acquired conditions (HACs). ${ }^{24}$ Second, extra days in the LTCH substantially increase the likelihood of inpatient mortality or readmission to an acute-care hospital. ${ }^{25}$

To cleanly link longer stays to a greater risk of adverse events, we face the empirical challenge that a patient's length of stay is likely related to her unobservable (to the econometrician) health status, which also affects the chances of her experiencing an adverse event. For instance, suppose that whether or not a patient suffers an adverse event is determined by a simple threshold crossing model,

$$
y_{i}= \begin{cases}1 & y_{i}^{*} \geq 0 \\ 0 & y_{i}^{*}<0\end{cases}
$$

where the latent variable $y_{i}^{*}$ is

$$
y_{i}^{*}=X_{i} \beta+\delta L O S_{i}+\epsilon_{i}
$$

Here, $X_{i}$ is a vector that captures all observable, exogenous hospital and patient characteristics; $L O S_{i}$ is the the number of days spent in the hospital; and $\epsilon_{i}$ are unobservable factors that affect whether the patient has an adverse event, such as her underlying susceptibility to getting an infection. An endogeneity problem arises from this specification because $\epsilon_{i}$ may be correlated

\footnotetext{
${ }^{23}$ The results from the first four models are robust to geographic controls like state fixed effects.

${ }^{24}$ Starting in FY2015, after our data ends, the ACA established the "Hospital-Acquired Condition Reduction Program" to incentivize hospitals to reduce HACs by adjusting payments to the worst-performing hospitals with respect to risk-adjusted HAC quality measures. See https://www.cms.gov/Medicare/ Medicare-Fee-for-Service-Payment/AcuteInpatientPPS/HAC-Reduction-Program.html for more details. The deficit Reduction Act of 2005 required CMS to identify HACs that were high in cost or volume and could reasonably have been prevented by the hospital. As a result CMS has defined a list of twelve HACs that are most common and costly. For more details see: https://www.cms.gov/Medicare/Medicare-Fee-for-Service-Payment/ HospitalAcqCond/Downloads/FY_2013_Final_HACsCodeList.pdf.

${ }^{25}$ Einav et al. (2016) investigate whether the payment discontinuity results in an increase in 30-day mortality and do not find an effect. In contrast, we use the SSO threshold as an exogenous shifter to measure the marginal impact of an additional day in an LTCH on several health outcomes.
} 
Table 4: Probit Marginal Effects by LTCH Type, DRG 207 at Day 29

\begin{tabular}{|c|c|c|c|c|}
\hline \multirow[b]{2}{*}{ Model \#/Partition } & \multicolumn{2}{|c|}{ Predicted Prob. of Discharge } & \multirow{2}{*}{$\begin{array}{c}\text { Hazard } \\
\text { Ratio }^{1}\end{array}$} & \multirow{2}{*}{$\begin{array}{c}\text { Ratio of } \\
\text { Hazard Ratios }\end{array}$} \\
\hline & SSO Threshold Day & Preceding Day & & \\
\hline \multicolumn{5}{|l|}{ Model \#1: } \\
\hline For-profit & $\begin{array}{l}9.28^{* * *} \\
(0.363)\end{array}$ & $\begin{array}{c}0.967^{* * *} \\
(0.052)\end{array}$ & $\begin{array}{l}9.60^{* * *} \\
{[0.000]}\end{array}$ & $\begin{array}{l}1.92^{* * *} \\
{[0.000]}\end{array}$ \\
\hline Non-profit & $\begin{array}{l}7.61^{* * *} \\
(0.604)\end{array}$ & $\begin{array}{l}1.53^{* * *} \\
(0.160)\end{array}$ & $\begin{array}{l}4.99^{* * *} \\
{[0.000]}\end{array}$ & \\
\hline \multicolumn{5}{|l|}{ Model \#2: } \\
\hline Kindred and Select ${ }^{5}$ & $\begin{array}{l}9.54^{* * *} \\
(0.426)\end{array}$ & $\begin{array}{l}0.95^{* * *} \\
(0.059)\end{array}$ & $\begin{array}{c}10.01^{* * *} \\
{[0.000]}\end{array}$ & $\begin{array}{l}1.64^{* * *} \\
{[0.000]}\end{array}$ \\
\hline Other & $\begin{array}{l}8.02^{* * *} \\
(0.458)\end{array}$ & $\begin{array}{l}1.31^{* * *} \\
(0.101)\end{array}$ & $\begin{array}{l}6.12^{* * *} \\
{[0.000]}\end{array}$ & \\
\hline \multicolumn{5}{|l|}{ Model \#3: } \\
\hline After Acquisition ${ }^{6}$ & $\begin{array}{c}11.07^{* * *} \\
(0.662)\end{array}$ & $\begin{array}{l}0.66^{* * *} \\
(0.089)\end{array}$ & $\begin{array}{c}16.82^{* * *} \\
{[0.000]}\end{array}$ & $\begin{array}{l}2.51^{* * *} \\
{[0.000]}\end{array}$ \\
\hline Before Acquisition ${ }^{7}$ & $\begin{array}{l}9.94^{* * *} \\
(0.778)\end{array}$ & $\begin{array}{l}1.48^{* * *} \\
(0.172)\end{array}$ & $\begin{array}{l}6.70^{* * *} \\
{[0.000]}\end{array}$ & $\begin{array}{l}0.89^{* * *} \\
{[0.000]}\end{array}$ \\
\hline Never Acquired & $\begin{array}{l}8.53^{* * *} \\
(0.357)\end{array}$ & $\begin{array}{l}1.13^{* * *} \\
(0.067)\end{array}$ & $\begin{array}{l}7.54^{* * *} \\
{[0.000]}\end{array}$ & \\
\hline \multicolumn{5}{|l|}{ Model \#4: } \\
\hline $\mathrm{HwH}$ & $\begin{array}{c}11.31^{* * *} \\
(0.508)\end{array}$ & $\begin{array}{l}1.20^{* * *} \\
(0.099)\end{array}$ & $\begin{array}{l}9.42^{* * *} \\
{[0.000]}\end{array}$ & $\begin{array}{l}1.28^{* * *} \\
{[0.000]}\end{array}$ \\
\hline Not $\mathrm{HwH}$ & $\begin{array}{l}7.73^{* * *} \\
(0.344)\end{array}$ & $\begin{array}{l}1.05^{* * *} \\
(0.066)\end{array}$ & $\begin{array}{l}7.34^{* * *} \\
{[0.000]}\end{array}$ & \\
\hline \multicolumn{5}{|c|}{ Model \#5, includes LTCH FEs: } \\
\hline Black $^{5}$ & $\begin{array}{l}8.43^{* * *} \\
(0.383)\end{array}$ & $\begin{array}{l}0.84^{* * *} \\
(0.080)\end{array}$ & $\begin{array}{l}9.94^{* * *} \\
{[0.000]}\end{array}$ & $\begin{array}{c}1.27^{*} \\
{[0.047]}\end{array}$ \\
\hline Other & $\begin{array}{l}8.62^{* * *} \\
(0.328)\end{array}$ & $\begin{array}{l}1.17^{* * *} \\
(0.149)\end{array}$ & $\begin{array}{l}7.38^{* * *} \\
{[0.000]}\end{array}$ & $\begin{array}{c}0.94 \\
{[0.686]}\end{array}$ \\
\hline White & $\begin{array}{l}8.77^{* * *} \\
(0.281)\end{array}$ & $\begin{array}{l}1.12^{* * *} \\
(0.067)\end{array}$ & $\begin{array}{l}7.82^{* * *} \\
{[0.000]}\end{array}$ & \\
\hline \multicolumn{5}{|c|}{ Model \#6, includes LTCH FEs: } \\
\hline 65 and over & $\begin{array}{l}8.08^{* * *} \\
(0.353)\end{array}$ & $\begin{array}{l}0.99^{* * *} \\
(0.059)\end{array}$ & $\begin{array}{l}8.19^{* * *} \\
{[0.000]}\end{array}$ & $\begin{array}{c}1.06 \\
{[0.454]}\end{array}$ \\
\hline Under 65 & $\begin{array}{c}10.65^{* * *} \\
(0.353)\end{array}$ & $\begin{array}{l}1.38^{* * *} \\
(0.010)\end{array}$ & $\begin{array}{l}7.73^{* * *} \\
{[0.000]}\end{array}$ & \\
\hline
\end{tabular}

Note: Standard errors in parentheses. P-values in brackets. This sample contains only episodes of hospitalization that terminated in discharge to home care or nursing facilities. See also table notes from Table 3

${ }^{1}$ Square brackets contain the p-value from a Wald test for $H_{0}: H R=\frac{\Phi\left(\gamma_{0}+\gamma_{1} t+\gamma_{2} t^{2}+\mu_{0}\right)}{\Phi\left(\gamma_{0}+\gamma_{1} t+\gamma_{2} t^{2}+\mu_{-1}\right)}=1$.

${ }^{2}$ Brackets contain p-value for Wald test statistic for the ratios of risk ratios: $H_{0}: H R^{\text {type }} 1 / H R^{\text {type } 2}=1$.

${ }^{3}$ Ratio of hazard ratio for acquisition LTCHs and pre-acquisition LTCHs.

${ }^{4}$ Ratio of hazard ratio for pre-acquisition LTCHs and "never acquired" LTCHs.

${ }^{5}$ Ratio of hazard ratio for both "Black" and "Other" patients are relative to "White" patients. 
with $L O S_{i}$, and the sign of the bias is not clear. For instance, it may be that the patients who are most susceptible to adverse events tend to leave the LTCH earlier, either because they die shortly after admission or are readmitted to an acute-care hospital to receive more intensive treatment, outcomes that would bias a simple estimate of $\delta$ downwards. Conversely, their poor health may result in longer recovery times inside the LTCH relative to other patients, biasing $\delta$ upwards.

To obtain consistent estimates of $\delta$, we therefore must observe some variable that is correlated with a patient's length of stay but that is uncorrelated with the patient's health. The SSO threshold is ideal for this purpose: it is set by Medicare and uncorrelated with unobservable patient-specific conditions, though it clearly affects a patient's length of stay due to LTCHs' financial incentives. Specifically, we assume that a patient's length of stay is determined by

$$
L O S_{i}=X_{i} \alpha+\gamma S S O_{i}+u_{i}
$$

After controlling for hospital and patient characteristics, as well as DRG and year fixed effects, we find that for each additional day Medicare pushes out a DRG's SSO threshold, a patient's expected length of stay increases by 0.58 days.26

Given this exogenous shift, we can next identify the impact of a patient's length of stay on the likelihood of her experiencing adverse events, $\delta$, using two complementary frameworks: a linear probability model (LPM) and a probit model. An advantage of the LPM is that it allows for a direct application of IV methods with a rich set of controls, such as hospital-specific fixed effects. One drawback of the LPM, however, is that it may produce estimates for the marginal impact of an additional day in an LTCH that lie outside the unit interval. As such, we also estimate a probit model — with a more restrictive set of controls, because it is nonlinear that yields valid outcome probabilities for any patient and length of stay, which we then use in Section 7.2 to predict how changes in the payment system would affect the likelihood that a patient experiences an adverse event.

Table 5 shows our estimates of how a patient's length of stay impacts her chances of contracting any of the HACs classified by Medicare 27 The results for the LPM and probit models are remarkably consistent, indicating that the marginal impact of an additional day in an LTCH

\footnotetext{
${ }^{26}$ Estimates of this first stage equation are available in Table A4 of the online appendix.

${ }^{27}$ Each HAC is identified by a grouping of diagnosis (and sometimes procedural) codes. If at least one of the diagnosis codes (and, when relevant, a procedural code) is present on a claim, we judge that hospital stay to have developed the HAC. A complicating feature of the HAC data is that we are not always able to discern whether a HAC developed in the LTCH, or if it was present on admission, because although short-term care hospitals are required to report present-on-admission status on the claims, LTCHs are not. We address this issue in two ways. First, we focus on specific HACs that are more likely to have occurred in the LTCH than in a short-term hospital that the patient was potentially in prior to the LTCH. Second, we employ an instrumental variable strategy that accounts for measurement error of this type. The specific HACs we focus on are pressure ulcers (bed sores), falls and trauma, and catheter infections, which may be urinary tract or vascular catheter infections, and the frequency of these HACs are summarized in Table 6 below.
} 
raises the probability of contracting a HAC by between 1.2 and 1.3 percent compared to an underlying probability of 26.4 percent for all patients (see Table 6 for summary statistics). We interpret this as strong evidence that unnecessarily extending hospital stays by even a few days may have a substantial impact on health outcomes. Comparing our IV estimates to OLS, instrumenting for the endogenous length of stay shows that it actually has a larger causal impact on HACs, which may be because the sickest patients tend to have shorter LTCH stays.

Table 5: Second Stage Estimates, $\mathbb{P}($ Any HAC $)$

\begin{tabular}{lcccccc}
\hline & \multicolumn{2}{c}{ LPM } & \multicolumn{2}{c}{ LPM, Hosp. FEs } & \multicolumn{2}{c}{ IV Probit } \\
& OLS & IV & OLS & IV & Coef. & ME $^{1}$ \\
\hline Length of stay & $0.002^{* * *}$ & $0.012^{* * *}$ & $0.002^{* * *}$ & $0.012^{* * *}$ & $0.045^{* * *}$ & $0.013^{* * *}$ \\
& $(0.0001)$ & $(0.0023)$ & $(0.0001)$ & $(0.0025)$ & $(0.0035)$ & $(0.0010)$ \\
Black & & & & & & \\
& $0.047^{* * *}$ & $0.035^{* * *}$ & $0.038^{* * *}$ & $0.023^{* * *}$ & $0.071^{* * *}$ & $0.020^{* * *}$ \\
Over 65 & $(0.0024)$ & $(0.0038)$ & $(0.0019)$ & $(0.0040)$ & $(0.0141)$ & $(0.0039)$ \\
& $-0.052^{* * *}$ & $-0.048^{* * *}$ & $-0.050^{* * *}$ & $-0.046^{* * *}$ & $-0.118^{* * *}$ & $-0.033^{* * *}$ \\
& $(0.0019)$ & $(0.0022)$ & $(0.0018)$ & $(0.0020)$ & $(0.0117)$ & $(0.0031)$
\end{tabular}

LTCH Type

$\begin{array}{lccc}\text { For-profit, standalone } & -0.004 & -0.026^{* * *} & -0.093 \\ & (0.0031) & (0.0060) & (0.0130) \\ \text { Non-profit, HWH } & -0.009^{*} & -0.014^{* *} & -0.043^{*} \\ & (0.0043) & (0.0050) & (0.015) \\ \text { Non-profit, standalone } & -0.001 & -0.031^{* * *} & -0.117 \\ & (0.0042) & (0.0087) & (0.020)\end{array}$

\begin{tabular}{llllll}
\hline Year FE & $X$ & $X$ & $X$ & $X$ & $X$ \\
DRG FE & $X$ & $X$ & $X$ & $X$ & $X$ \\
Hospital FE & & & $X$ & $X$ & \\
\hline
\end{tabular}

Note: Standard errors (in parentheses) are clustered at the hospital $\times$ DRG level. The sample includes the nine most common DRGs for years from 2004 to 2013. The reference LTCH type is for-profit HWH.

1 Average marginal effects from the IV Probit model.

In Table 6, we report the marginal effect of an additional day in an LTCH on a variety of adverse events. In the top panel of the table, we consider the effect on specific subgroups of HACs: pressure ulcers, trauma, and catheter infections. In the bottom panel, we consider the impact of an additional day on negative outcomes related to discharge destination: dying in the LTCH or being transferred back to an acute care hospital. For comparison, we also report the baseline frequency of the different outcomes in the table's first column and the standard deviation in the 
second column. These results, which are robust to the precise modeling assumptions used and a variety of patient and hospital controls, imply that additional days in the hospital substantially increase the probability of adverse events. For example, we find that each extra day in the LTCH increases the likelihood of a pressure ulcer by between 11.3-15.2 percent. Or, considering the most extreme adverse event, we find that each extra day increases the likelihood that the patient dies in the LTCH by 2-3 percent.

Table 6: Marginal Effects of Length of Stay on Adverse Outcomes

\begin{tabular}{|c|c|c|c|c|c|c|}
\hline & \multirow[b]{2}{*}{ Mean } & \multirow[b]{2}{*}{ Std. Dev. } & \multicolumn{4}{|c|}{ Average Marginal Effects } \\
\hline & & & OLS & $\begin{array}{c}\text { IV } \\
\text { No Hosp. FE }\end{array}$ & $\begin{array}{c}\text { IV } \\
\text { Hosp. FE }\end{array}$ & $\begin{array}{c}\text { IV } \\
\text { Probit }\end{array}$ \\
\hline $\mathbb{P}($ Any $\mathrm{HAC})$ & 0.264 & 0.439 & $\begin{array}{l}0.002^{\text {*** }} \\
(0.0001)\end{array}$ & $\begin{array}{l}0.012^{\text {*** }} \\
(0.0020)\end{array}$ & $\begin{array}{l}0.012^{* * *} \\
(0.0025)\end{array}$ & $\begin{array}{l}0.013^{* * *} \\
(0.0011)\end{array}$ \\
\hline $\mathbb{P}($ Pressure Ulcer $)$ & 0.151 & 0.358 & $\begin{array}{l}0.001^{\text {*** }} \\
(0.0001)\end{array}$ & $\begin{array}{l}0.023^{* * *} \\
(0.0026)\end{array}$ & $\begin{array}{l}0.023^{* * *} \\
(0.0026)\end{array}$ & $\begin{array}{l}0.017^{\text {*** }} \\
(0.0004)\end{array}$ \\
\hline $\mathbb{P}($ Fall or trauma $)$ & 0.013 & 0.113 & $\begin{array}{c}0.000^{* * *} \\
(0.00001)\end{array}$ & $\begin{array}{c}0.000 \\
(0.0004)\end{array}$ & $\begin{array}{c}-0.000 \\
(0.0004)\end{array}$ & $\begin{array}{l}0.00027 \\
(0.0004)\end{array}$ \\
\hline $\mathbb{P}$ (Catheter Infection) & 0.025 & 0.153 & $\begin{array}{c}0.001^{* * *} \\
(0.00003)\end{array}$ & $\begin{array}{c}0.001 \\
(0.0005)\end{array}$ & $\begin{array}{c}0.001 \\
(0.0006)\end{array}$ & $\begin{array}{c}0.0012 \\
(0.0016)\end{array}$ \\
\hline $\mathbb{P}$ (Disch. Death) & 0.177 & 0.382 & $\begin{array}{c}-0.005^{* * *} \\
(0.0001)\end{array}$ & $\begin{array}{c}0.005^{* *} \\
(0.0019)\end{array}$ & $\begin{array}{l}0.006^{* * *} \\
(0.0017)\end{array}$ & $\begin{array}{c}0.004^{*} \\
(0.0018)\end{array}$ \\
\hline $\mathbb{P}$ (Disch. Death/Hosp.) & 0.297 & 0.458 & $\begin{array}{c}-0.008^{* * *} \\
(0.0001)\end{array}$ & $\begin{array}{l}0.010^{* * *} \\
(0.0027)\end{array}$ & $\begin{array}{l}0.010^{* * *} \\
(0.0021)\end{array}$ & $\begin{array}{c}0.006^{*} \\
(0.0018)\end{array}$ \\
\hline $\mathbb{P}($ Disch. Home $)$ & 0.275 & 0.448 & $\begin{array}{c}0.000 \\
(0.0001)\end{array}$ & $\begin{array}{c}-0.017^{* * *} \\
(0.0026)\end{array}$ & $\begin{array}{l}-0.015^{* * *} \\
(0.0020)\end{array}$ & $\begin{array}{r}-0.012^{\text {*** }} \\
(0.0013)\end{array}$ \\
\hline
\end{tabular}

Note: Marginal effects of an additional day in the hospital on the probability of various outcomes. Standard errors (in parentheses) are clustered at the hospital $\times$ DRG level. The sample includes the nine most common DRGs for years from 2004 to 2013.

These results indicate that, by influencing LTCHs' discharge decisions, Medicare's payment policies not only directly affect costs, but also affect the health of patients. In the following section, we propose a dynamic model of LTCHs' discharge decisions that can be used to predict the impact alternative payment policies would have along both of these dimensions.

\section{Quantifying the Response to Financial Incentives}

The results above show that LTCHs respond to financial incentives when making discharge decisions. In this section, we propose a dynamic model to isolate the effect of Medicare's payment policy on discharges, which then allows us to analyze how changing the reimbursement scheme 
would influence hospitals' behavior.

Before introducing the model, we should note that it is just one of several components that would be required to conduct a full welfare analysis of Medicare's payment policies. At least two key ingredients are missing. First, we cannot recover the marginal benefit patients get from an additional day of care, as we lack the necessary data on patients' medical histories to do so. Although we do have some measures correlated with patient outcomes, as discussed in Section 5, they do not capture the full extent of a patient's well-being. Second, we do not have clear information on the marginal costs of providing an additional day of treatment. Although we do have data on hospitals' cost-to-charge ratios that should be correlated with hospital costs, they are at best an indicator of average costs per day. As such, we view them as a potential control for cross-hospital differences in costs rather than as a direct measure of marginal costs.

Because we cannot directly measure hospitals' costs or patients' benefits, we instead rely on a structural model to recover the effect of payment policies on discharges. In the model, we will allow for a flexible DRG-specific length-of-stay effect that, under reasonable assumptions, controls for the impact of both marginal costs and patients' benefits on hospitals' discharge decisions. If our model shows that the distribution of discharges and its key moments, such as the average length of stay, vary substantially in response to alternative payment schemes, then determining the optimal payment scheme represents an important policy goal because of its influence on hospitals' choices. Moreover, our analysis gives us a precise understanding of how the policy affects a patient's length of stay. Under the reasonable assumption that treatment costs rise as a patient stays longer in the hospital, the length of stay itself becomes a useful metric for analyzing the impact of payment policies on hospital costs. Finally, our results highlight the extent to which payment policies can be used to influence lengths of stay and establish how additional days of hospital treatment affect patient outcomes.

\subsection{A Model of Hospital Discharge Decisions}

We model the daily decision of an LTCH to discharge a patient 28 The patient arrives at the LTCH at $t=0$. Each day, the LTCH receives a flow utility for treating the patient equal to

$$
u_{t}=\lambda_{t}+\alpha p_{t}
$$

where $\lambda_{t}$ represents the non-revenue benefits and costs of keeping the patient for another night 29 The key assumption here is that these benefits can be represented as a function of the number

\footnotetext{
${ }^{28}$ While in the full model we will allow for both hospital and patient heterogeneity, we suppress them in this section for expositional clarity. For example, when estimating the model we will allow for an LTCH's response to daily payments to depend on its for-profit status.

${ }^{29}$ We use the notation $u_{t}$ for flow payoffs since we are not assuming that the LTCH is necessarily profit maximizing.
} 
of days since a patient was admitted, as well as observable hospital and patient characteristics. The payment $p_{t}$ is the marginal payment for treating a patient on day $t$, as defined by Medicare's PPS, such that

$$
p_{t}= \begin{cases}p & t<t^{m} \\ P-\left(t^{m}-1\right) \cdot p & t=t^{m} \\ 0 & t>t^{m}\end{cases}
$$

where $p$ represents the per-diem payment for stays shorter than the SSO threshold, $t^{m}$. We estimate $p$ from patient-level payment data and allow it to depend on hospital and patient characteristics. The variable $P$ is the payment governed by the long-term PPS, so $P-\left(t^{m}-1\right) \cdot p$ is the marginal payment on the day the patient crosses the SSO threshold. Finally, once the patient crosses the threshold, the hospital receives no additional payments.

The LTCH decides each day whether or not to discharge the patient. In doing so, it weighs the financial incentives of discharging today against the costs of providing further treatment and the numerous non-pecuniary reasons to keep the patient in the facility (e.g., the risk incurred by releasing the patient too early, the disutility the patient experiences from unnecessary treatments, and the marginal benefit of treatment to the patient). If the patient is discharged, then treatment ends and the LTCH can use the bed to treat other patients. We normalize the value of an open bed to 0 , so that the flow value of treating a patient on day $t$ is relative to the value of having an open bed. Otherwise, the patient continues to be treated and the LTCH faces a new discharge decision tomorrow.

In deciding whether or not to discharge the patient, the hospital observes a vector of choicespecific idiosyncratic shocks $\varepsilon_{t}=\left(\varepsilon_{k t}, \varepsilon_{d t}\right)$, the components of which relate to keeping or discharging the patient, respectively. The Bellman equation for the LTCH's dynamic problem is therefore

$$
V_{t}\left(\varepsilon_{t}\right)=u_{t}+\max \left\{\varepsilon_{k t}+\delta E V_{t+1}, \varepsilon_{d t}\right\}
$$

where $E V_{t+1}$ is the expected continuation value of having a patient at time $t+1$. Because the model is non-stationary, we assume a finite time horizon and define a parameter $\Omega=E V_{T+1}$ that represents the termination value of treating a patient beyond day $T$ (i.e., not discharging on day $T$ ). We then estimate this value as a part of the model, allowing a distinct $\Omega$ for each DRG. We set $T \gg t_{m}$ and high enough relative to the average length of stay in the data so that the vast majority of patients are discharged prior to day $T$.

Following the literature on dynamic models, we assume that $\varepsilon$ is distributed according to a Type-I extreme value distribution, so the probability that the patient is discharged on day $t$ (given no earlier discharge) is

$$
D_{t}=\operatorname{Pr}(\text { discharge on } \mathrm{t} \mid \text { no discharge } 1 \ldots t-1)=\frac{1}{1+e^{\delta E V_{t+1}}}
$$


Applying the inclusive sum formula for the extreme value distribution (Rust 1987), the expected value of a patient on day $t$ before drawing $\varepsilon_{t}$ is

$$
E V_{t}=u_{t+1}+\log \left(\exp \left(\delta E V_{t+1}\right)+1\right)
$$

The model can then be solved via backward induction from the terminal period $T$ given parameters $\left(\lambda_{t}, \alpha, \delta\right)$ and the payment policy $p_{t}$ to recover continuation values and discharge probabilities for each day.

\subsection{Estimation}

We estimate the model using the nine most common DRGs in the data. Our estimation sample is summarized in Table A5 in Online Appendix A.

\subsubsection{Payment Policies}

The first step in our estimation is to recover the payment policy for each hospital-patient pair. We assume that hospitals form expectations about the monetary value of each additional day it keeps a patient in the hospital based on Medicare's payment policy. Following (6), we assume that the payment policy reflects a per-diem payment for stays shorter than the SSO threshold and a single fixed payment for all stays that exceed the threshold, which we estimate using data on total payments, length of stay, and hospital characteristics 31

We estimate the per-diem rate using a linear model that allows for a distinct rate for each hospital, year, and DRG on a sample restricted to include only observations with lengths of stay shorter than the SSO threshold:

$$
r_{i h y}=\zeta_{y}\left(Z_{i}, X_{h}\right) d_{i h y}+\eta_{i h y}
$$

where $r_{i h y}$ is the total payment for patient $i$ at hospital $h$ in year $y$. The length of stay is denoted by $d_{i h y}$, and $\eta_{i h y}$ represents measurement error in payments and unanticipated shocks to total payments. The estimation sample includes only those observations such that $d_{y h i}<t_{y}^{m}$, where $t_{y}^{m}$ is the SSO threshold for year $y$ (this will also vary with the specific DRG for patient $i$ ). The $\zeta$ parameter represents a per-diem payment for short stays - using the notation of (6), $p=\hat{\zeta}$ - and is allowed to vary by patient characteristics, $Z_{i}$, and hospital characteristics, $X_{h}$. Our specification allows $\zeta$ to be a function of the year, patient DRG, hospital MSA, and hospital type, where the hospital type is the interaction of for-profit and $\mathrm{HwH}$ status, resulting in the

\footnotetext{
${ }^{30}$ Note that Euler's constant term in this formula is implicitly absorbed into $\lambda_{t}$ without loss of generality.

${ }^{31}$ Strictly speaking, a per-diem rate factors into payments for only a subset of short stays (see Section 2 as well as Online Appendix C). However, Figure 1 suggests that a daily per-diem rate does approximate the payment structure laid out by (6).
} 
functional form

$$
r_{i h y}=\left(\zeta_{y, D R G_{i}}^{1}+\zeta_{y, M S A}^{2}+\zeta_{y, t y p e}^{3}\right) d_{i h y}+\eta_{i h y}
$$

In choosing this form, we have tried to allow for a great deal of flexibility in estimating the payment policy. There is a distinct $\zeta^{1}$ for each year from 2004-2013 and for each of the nine DRGs; this captures the differences in Medicare payments for different conditions over time. There is also a distinct $\zeta^{2}$ for each year and MSA combination; this captures geographic and temporal differences in wages, a feature of Medicare's SSO payment policy. Finally, there is a distinct $\zeta^{3}$ for each year and LTCH type ${ }^{32}$ this allows for the possibility that different types of hospitals have different cost-reporting policies or strategies for extracting Medicare payments. Per-diem payments for short stays, $p$, are then set equal to $\hat{\zeta}_{y, D R G_{i}}^{1}+\hat{\zeta}_{y, M S A}^{2}+\hat{\zeta}_{y, t y p e}^{3}$ for each day up to the SSO threshold.

Our data contain 61,590 patients who were released prior to the SSO threshold, and we include 1,874 parameters in Specification (11) to flexibly estimate a payment rate for each observation based on patient and hospital characteristics. Including this degree of heterogeneity allows us to explain most of the variation in payments: the OLS model achieves an $R^{2}$ of 0.964 and an adjusted $R^{2}$ of 0.963 . In panel (a) of Table A6 in Online Appendix A, we report the mean, median, 25th percentile, and 75th percentile for the distribution of per-diem payment rates by hospital type. For-profit standalone LTCHs have, on average, per-diem rates \$89 lower than non-profit standalone LTCHs, whereas for-profit HwHs and for-profit standalone LTCHs have only a $\$ 7$ difference between them. The column of interquartile ranges in Table A6, however, shows considerable heterogeneity in the per-diem rates within hospital types. Much of this heterogeneity is explained by differences in per-diem payments across DRGs, as shown in Online Appendix Table A5.

The full PPS payment, $P$, is paid out if the patient stays past the SSO threshold, which we compute directly from the payment policy, as explained in Section 2 and Online Appendix C. The policy adjusts the full payment based on the patient's DRG and a wage index for the hospital's location (here, the CBSA). Thus, $P$ is specific to each hospital, year, and DRG. The discontinuity in payments is then the difference between $P$ and the sum of the per-diem payments up to the day immediately preceding the magic day. Panel (b) of Table A6 contains descriptive statistics for these full payments, breaking them out by hospital types. The differences in full payments across hospital types primarily reflect differences in location (as wage indices vary by geography), weightings across years, and the case-mix of DRGs admitted to each hospital. Among non-profit hospitals, the difference in mean full PPS payments at $\mathrm{HwH}$ and standalone LTCHs is $\$ 1,079$, a relatively small difference compared to the $\$ 3,059$ difference between forprofit $\mathrm{HwH}$ and standalone LTCHs. Again, these differences stem from the varying geographic

\footnotetext{
${ }^{32} \mathrm{LTCH}$ type refers to the interaction between for-profit status and HwH status. Thus, there are four types: for-profit and $\mathrm{HwH}$, for-profit and standalone, non-profit and $\mathrm{HwH}$ and non-profit and standalone.
} 
locations of hospitals, how many long-term stays each hospital has each year, and how the DRG case-mix varies across hospitals.

Table A5 illustrates how the DRG case-mix contributes to the variation in full payments. Full PPS payments range from an average of $\$ 78,749$ for DRG 207 to $\$ 27,153$ for DRG 949. An LTCH with more admissions for DRG 207 will therefore have a higher mean full PPS payment. Table A5 also shows that there is some variation in the DRG case-mix across LTCH types. For example, for-profit HwH LTCHs account for just 17 percent of total hospital stays but have 23 percent of DRG 207 stays. By contrast, for-profit standalone LTCHs account for 57 percent of hospital stays but have only 50 percent of DRG 207 stays.

Finally, Panel (c) of Table A6 contains the resulting magic day payments. Magic day payments are highest, on average, at for-profit HwH LTCHs. This is partly because they have more DRG 207 cases. Once again, there is substantial variation in magic day payments, largely due to differences across DRGs. Among for-profit HwH LTCHs, the 25th percentile magic day payment is $\$ 8,965$, while the 75 th percentile is $\$ 29,478$. As with our discussion above, all of this variation will be useful for identifying how financial incentives affect discharges.

\subsubsection{Parameterization}

For our parameterization of $\lambda_{t}$, recall that these parameters represent the costs and non-pecuniary benefits of keeping a patient in the hospital on day $t$. As such, we allow them to be a function of the time spent in the hospital and, because they likely vary by diagnosis, we allow this function to be fully interacted with the patient's DRG. In addition, we include an estimate of hospitalyear-specific average daily costs in order to capture heterogeneity across hospitals. Our estimate of average daily costs comes from an equation analogous to (10), except the dependent variable is the product of claim-specific covered charges and hospital-specific cost-to-charge ratios. For average costs, however, we do not limit the sample to only those episodes of hospitalization shorter than the SSO threshold. Our cost estimates appear in Online Appendix Table A7.

In the data, we observe a weekly cycle in the probability of discharge, with discharges dropping off precipitously on Saturdays and Sundays. We account for this in the model by including a series of dummy variables for each day of the week. Our final specification of $\lambda_{t}$ thus takes the form

$$
\lambda_{i, t}=\gamma_{0, D R G}+\gamma_{1, D R G} t+\gamma_{2, D R G} t^{2}-\beta \hat{c}_{h}+\psi_{\text {day of week }}
$$

In a final parameterization, we allow $\alpha$ to vary by hospital and patient characteristics to capture any potential heterogeneity in how revenue affects discharges. Specifically, we allow for a different $\alpha$ for each of four LTCH types (for-profit $\mathrm{HwH}$, for-profit standalone, non-profit HwHs, and non-profit standalone), indexed by $k$, and include an additive term for the patient type (black and under 65 years of age), indexed by $z$ : 


$$
\alpha=\alpha_{k}+\alpha_{z}
$$

\subsubsection{Likelihood}

We use the dynamic model to estimate $\theta=\{\lambda, \alpha\}{ }^{33}$ We observe each patient's day of discharge and have the payment plan associated with each patient, $p_{h i}$, estimated from the previous section. As LTCHs behave optimally according to (8), each patient's contribution to the model likelihood is denoted

$$
\operatorname{Pr}\left(d_{h i} \mid p_{h i}, \theta\right)=D_{t}\left(p_{h i} ; \theta\right) \prod_{\tau=1}^{d_{h i}-1}\left(1-D_{\tau}\left(p_{h i} ; \theta\right)\right),
$$

where $D_{t}\left(p_{h i} ; \theta\right)$ is the probability of a patient being discharged on day $t$ given that she has not been discharged prior to $t$, as defined in (8). Given that optimal decisions are independent across patients, the likelihood function is

$$
L(\theta)=\prod_{i=1}^{N} \operatorname{Pr}\left(d_{h i} \mid p_{h i}, \theta\right)
$$

\section{Estimation Results and Counterfactual Policy Analysis}

We begin this section by presenting our estimates of the model outlined above. We then use the recovered parameters from our model to explore how alternative payment policies would affect discharges, and, consequently, Medicare expenditures and patient outcomes.

\subsection{Estimation Results}

Table 7 presents estimation results for two specifications of the model that differ based on the form of $\lambda$ in equation (12) and $\alpha$, the payment effect. The model fits the observed discharge patterns quite closely (see Figure A3 in Online Appendix E). The key parameter of interest, $\alpha$, shows how payments influence discharge decisions. For all hospital types, $\alpha$ is positive and significant, indicating that the promise of future payments reduces the probability of discharge on any given day. Our results also show that hospital types differ in how they respond to financial incentives, with for-profit HwHs being the most responsive and non-profit standalones the least. The differences between every possible pair of $\alpha$ coefficients are statistically significant at the 1 percent level, and the magnitudes suggest the differences are economically meaningful as well. The $\alpha$ coefficient for for-profit HwHs is as much as 56 percent larger than it is for non-profit standalone LTCHs, depending only slightly on the specification.

\footnotetext{
${ }^{33}$ Given that the time periods are days and we have a finite horizon, we set the discount factor to $\delta=1$. By way of comparison, an annual discount rate of 0.95 is equivalent to a daily discount rate of 0.99986 .
} 
In column (2), we add controls for patients' race and age in the functional form of $\alpha$. These results suggest that payments play a larger role in the timing of discharges for black and older patients. To put these numbers in context, simulations of the model show that for the nine pooled DRGs in our analysis, the average length of stay for black patients is 28.8 days, whereas the average length of stay for non-black patients is 1.4 days shorter. Coupled with these longer stays is a greater probability of a black patient remaining at the hospital until the magic day: 82 percent of black patients remain in the hospital until the SSO threshold compared to only 77 percent of non-black patients.

\subsection{Simulating Alternative Reimbursement Schemes}

We can now use the parameters estimated from the model above to evaluate how changes to the payment scheme would affect discharges. To do so, we re-solve for hospitals' optimal discharge policies under three alternative payment schedules (keeping other parameters constant), and determine how these policies impact the distribution of discharges. In doing so, it is important to note that our model takes the inflow of patients and the continued operation of hospitals as given, whereas if these policies were actually implemented, hospitals may respond by either changing the rate of admissions, the composition of admissions, or the decision to operate altogether. Because we have little evidence that patient characteristics have changed over our ten year sample of data, especially following the change to the very short stay outlier payment policy in 2013 when hospitals potentially faced a strong impetus to screen patients more selectively, we do not believe selection bias undermines our results. Strictly speaking, however, our counterfactuals only provide insight on how alternative policies would affect patients currently being treated at LTCHs.

We consider three separate counterfactual payment policies. The first makes hospital payments independent of the length of stay, which illustrates the extent to which the current payment policy affects discharges. In the second counterfactual, we consider a recent proposal that would remove the discontinuity associated with the SSO threshold but still provide smaller payments for short-stay visits. Finally, we analyze a cost-plus policy that is similar to how Medicare reimbursed LTCHs prior to 2003. In Figure 8, we compare simulated discharge patterns from the baseline model to those simulated for the three alternative payment policies. The analysis that follows focuses on the pooled DRGs, shown in the left-hand column of Figure 8, while the righthand column isolates patients with DRG 207 in order to facilitate comparisons with Section 4. Table 8 then contains key comparisons between the baseline and counterfactual outcomes.

For our first counterfactual, we consider the case where payments do not depend on a patient's length of stay, meaning that the marginal payment for an additional day of treatment is zero. In principle, this could be accomplished by paying LTCHs a lump sum for each admission, as with a traditional PPS. In practice, the temptation for LTCHs to game the system by admitting and 


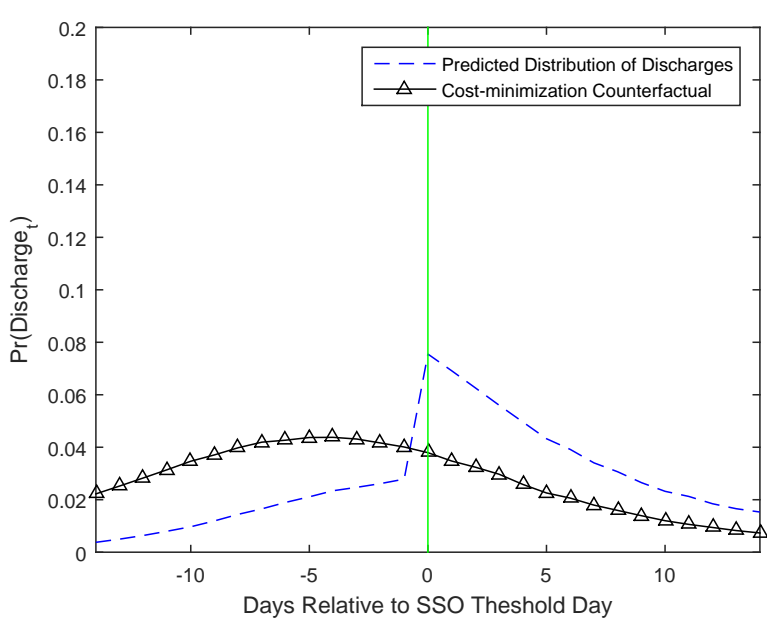

(a) Counterfactual 1, all DRGs

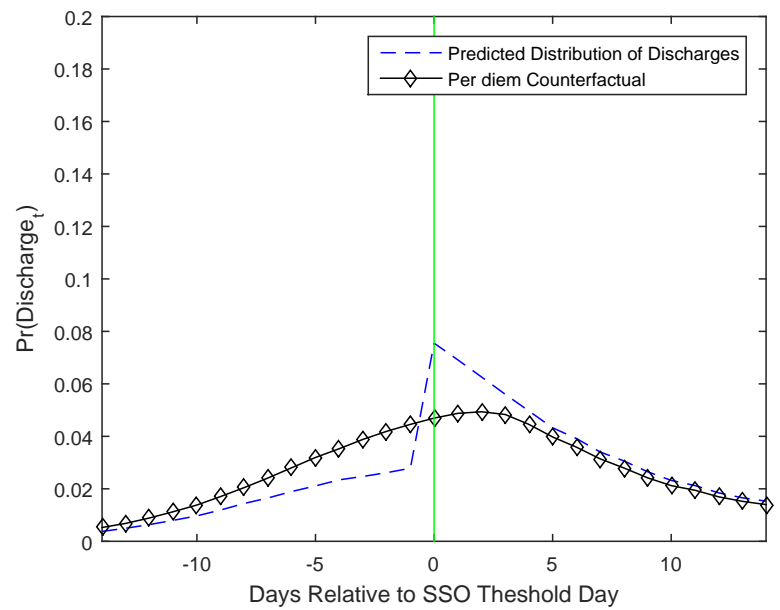

(c) Counterfactual 2, all DRGs

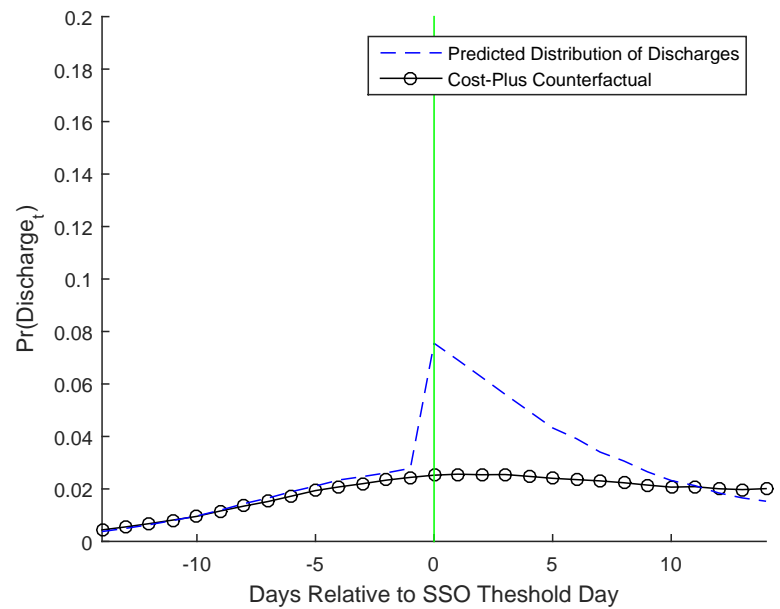

(e) Counterfactual 3, all DRGs

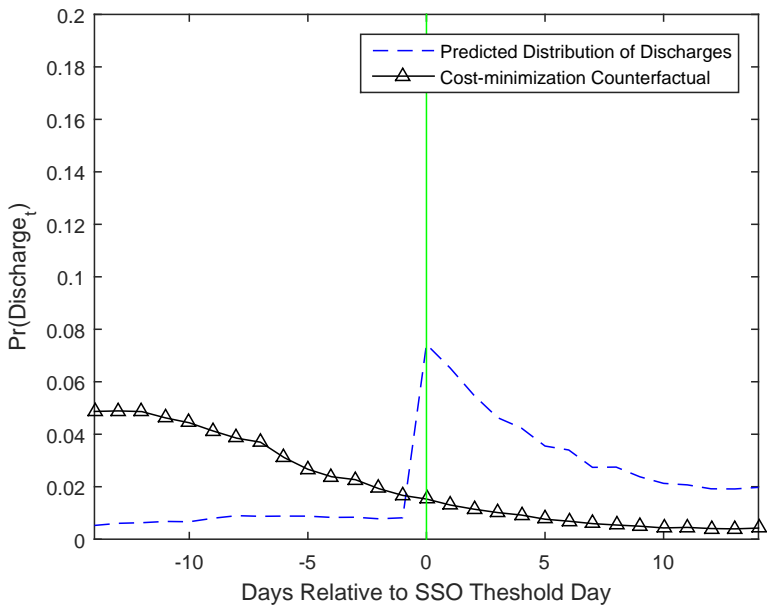

(b) Counterfactual 1, DRG 207

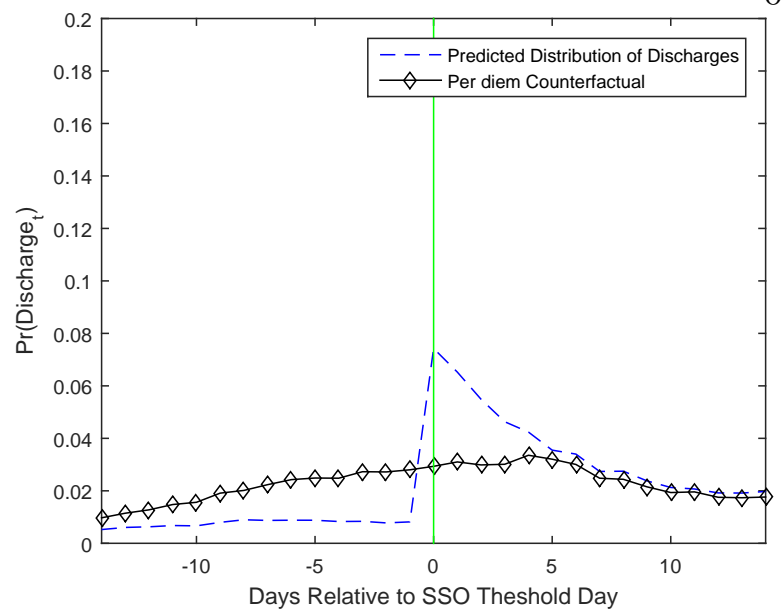

(d) Counterfactual 2, DRG 207

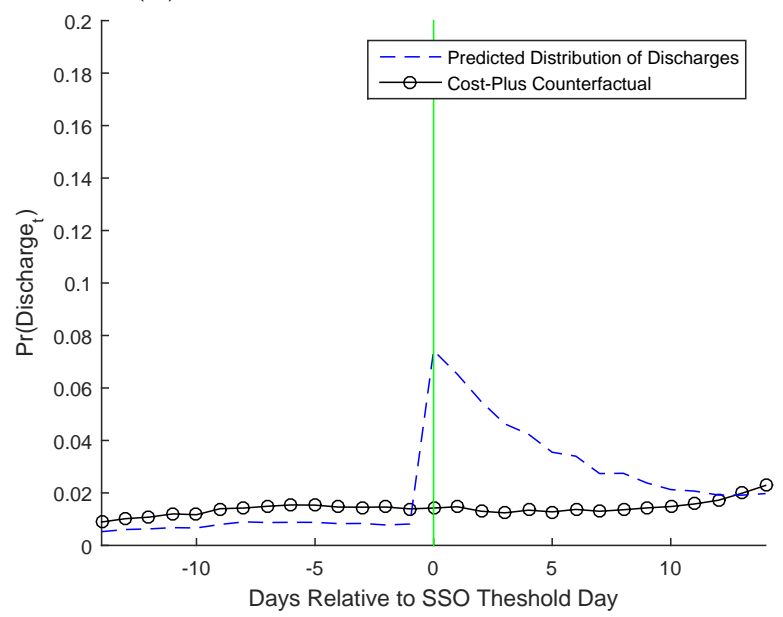

(f) Counterfactual 3, DRG 207

Figure 8: Predicted discharge probabilities for baseline model counterfactual scenarios 
Table 7: Model Estimates

\begin{tabular}{|c|c|c|c|}
\hline & & (1) & (2) \\
\hline \multicolumn{4}{|l|}{ Hospital Types } \\
\hline \multicolumn{2}{|c|}{ For-profit, $\mathrm{HwH}$} & $\begin{array}{c}0.876^{* * *} \\
(0.012)\end{array}$ & $\begin{array}{c}0.889^{* * *} \\
(0.012)\end{array}$ \\
\hline \multicolumn{2}{|r|}{ For-profit, standalone } & $\begin{array}{c}0.761^{* * *} \\
(0.006)\end{array}$ & $\begin{array}{c}0.773^{* * *} \\
(0.006)\end{array}$ \\
\hline \multicolumn{2}{|r|}{ Non-profit, $\mathrm{HwH}$} & $\begin{array}{c}0.667^{* * * *} \\
(0.016)\end{array}$ & $\begin{array}{c}0.675^{* * *} \\
(0.016)\end{array}$ \\
\hline \multicolumn{2}{|r|}{ Non-profit, standalone } & $\begin{array}{c}0.561^{* * *} \\
(0.011)\end{array}$ & $\begin{array}{c}0.571^{* * *} \\
(0.011)\end{array}$ \\
\hline \multicolumn{4}{|l|}{ Patient Types } \\
\hline \multicolumn{3}{|c|}{ Black } & $\begin{array}{c}0.164^{* * *} \\
(0.012)\end{array}$ \\
\hline \multicolumn{2}{|r|}{ Under 65 years old } & & $\begin{array}{c}-0.143^{* * *} \\
(0.003)\end{array}$ \\
\hline \multicolumn{2}{|c|}{ Day of week dummies } & & $\mathrm{X}$ \\
\hline \multicolumn{2}{|c|}{ Average daily cost $(\beta)$, interacted with four hospital types } & $\mathrm{X}$ & $\mathrm{X}$ \\
\hline \multicolumn{2}{|c|}{ DRG specific $\lambda$} & $\mathrm{X}$ & $\mathrm{X}$ \\
\hline \multicolumn{2}{|l|}{ DRG specific $\Omega$} & $\mathrm{X}$ & $\mathrm{X}$ \\
\hline \multicolumn{4}{|l|}{$N=377,513$} \\
\hline
\end{tabular}

quickly discharging healthy patients would still remain, so a feature like the current "very short stay" adjustment discussed in Online Appendix C would probably also have to be in place. The policy could also be implemented by nationalizing LTCHs and funding them independently of patient stays, similar to a VA hospital. Although neither of these options seem feasible in the short run, we view this scenario as a useful benchmark for examining how the distribution of discharges is affected by hospital payments.

Panel (a) of Figure 8 shows the predicted distribution of discharges (dashed line) for the nine DRGs pooled together, based on the estimates in column (2) of Table 7, while panel (b) shows the predicted discharges for just DRG 207. In each of these figures, we normalize the horizontal axis to display the day of discharge relative to the magic day, which varies over time. As expected, removing the incentive to keep patients past the SSO threshold eliminates the spike in discharges around the magic day. It is clear in the figure, however, that in addition to smoothing out discharges around the threshold, there is a substantial leftward shift in the entire distribution. Indeed, the discharge probability 10 days prior to the magic day is 3.5 times higher. Overall, patients are released much earlier when the financial incentives to delay discharge are eliminated: the average length of stay declines by 7.5 days relative to the baseline model, an 
Table 8: Counterfactual Outcomes

\begin{tabular}{|c|c|c|c|c|}
\hline & Baseline model & $\begin{array}{c}\text { Counter.1: } \\
\quad \alpha=0\end{array}$ & $\begin{array}{l}\text { Counter. 2: } \\
\text { Per-diem }\end{array}$ & $\begin{array}{c}\text { Counter. 3: } \\
\text { Cost-plus }\end{array}$ \\
\hline $\begin{array}{l}\text { Share of patients discharged } \\
\text { before magic day } \\
\text { Share of patients discharged } \\
\text { after magic day }\end{array}$ & 0.22 & 0.61 & 0.34 & 0.21 \\
\hline $\begin{array}{l}\text { Share of patients with longer } \\
\text { stay compared to baseline } \\
\text { Share of patients with shorter } \\
\text { stay compared to baseline }\end{array}$ & & $\begin{array}{l}0.00 \\
0.45\end{array}$ & $\begin{array}{l}0.04 \\
0.12\end{array}$ & $\begin{array}{l}0.41 \\
0.04\end{array}$ \\
\hline $\begin{array}{l}\text { Mean day of discharge } \\
\text { relative to magic day } \\
\text { St. dev. day of discharge }\end{array}$ & $\begin{array}{l}3.35 \\
7.66\end{array}$ & $\begin{array}{c}-3.22 \\
9.30\end{array}$ & $\begin{array}{l}2.20 \\
8.07\end{array}$ & $\begin{array}{c}5.85 \\
10.31\end{array}$ \\
\hline $\begin{array}{l}\text { Mean length of stay } \\
\text { Mean percent change in length of stay } \\
\text { relative to baseline }\end{array}$ & 27.66 & $\begin{array}{l}20.19 \\
-23\end{array}$ & $\begin{array}{c}26.46 \\
-3\end{array}$ & $\begin{array}{c}32.68 \\
26\end{array}$ \\
\hline $\begin{array}{l}\text { Of patients in the hospital } \\
3 \text { days prior to the magic day: } \\
\text { Percent held until the magic day } \\
\text { Percent discharged within } 3 \\
\text { days after the magic day }\end{array}$ & $\begin{array}{l}88 \\
29\end{array}$ & $\begin{array}{l}69 \\
25\end{array}$ & $\begin{array}{l}80 \\
24\end{array}$ & $\begin{array}{l}90 \\
12\end{array}$ \\
\hline $\begin{array}{l}\text { Mean payments }(\$ 1000 \mathrm{~s}) \\
\text { St. dev. payments } \\
\text { Percent change in payments } \\
\quad \text { relative to baseline }\end{array}$ & $\begin{array}{l}40.10 \\
22.13\end{array}$ & $\begin{array}{l}26.29 \\
15.35 \\
-26\end{array}$ & $\begin{array}{c}39.61 \\
20.20 \\
-4\end{array}$ & $\begin{array}{c}46.08 \\
23.39 \\
\\
30\end{array}$ \\
\hline $\begin{array}{l}\text { Mean Costs }(\$ 1000) \\
\text { St. dev. payments } \\
\text { Percent change in costs } \\
\quad \text { relative to baseline }\end{array}$ & $\begin{array}{l}37.08 \\
19.36\end{array}$ & $\begin{array}{c}26.42 \\
15.16 \\
-23\end{array}$ & $\begin{array}{c}35.45 \\
19.14 \\
-3\end{array}$ & $\begin{array}{c}43.87 \\
22.29 \\
25\end{array}$ \\
\hline
\end{tabular}

Note: Baseline model and counterfactuals based on simulations with 100,000 patient draws.

average reduction of 23 percent.

Given that LTCHs cannot be reimbursed based on length of stay in this counterfactual, it is difficult to gauge the full impact it would have on Medicare's costs. To still provide some informative estimates along this dimension, however, we assume Medicare reimburses hospitals with a lump-sum payment that equals their expected costs. This should make hospitals indifferent between operating and not operating without giving them an incentive to manipulate discharges in order to receive higher payments ${ }^{34}$ If we suppose these payments are equal to our average cost-per-day estimates for each hospital-DRG-year, Medicare would save, on average, $\$ 10,660$

\footnotetext{
${ }^{34}$ Of course, if hospitals were aware that their lump-sum payment were being calculated in this way, it would provide a potential incentive to lengthen treatments in order to increase future lump-sum payments. These concerns are outside the scope of our model.
} 
per patient. Over our entire sample that comprises patients with one of nine DRGs that were discharged to home or a nursing facility, the aggregate savings per year would be $\$ 403$ million.

Our second counterfactual simulates a reimbursement formula recently proposed by MedPAC to stem strategic discharges 35 The proposed payment system consists of a per-diem payment rate based on the full LTCH payment divided by the geometric mean length of stay, so we refer to this scheme as the "per-diem counterfactual." Under this system, Medicare would pay twice the per-diem rate on the first day, and then a per-diem rate on each day thereafter until reaching the full LTCH payment on the day preceding the mean length of stay. As a result, the reimbursement policy is completely linear until the mean length of stay is realized, at which point the reimbursement ceases, as we illustrate in panel (a) of Figure A4 in Online Appendix E. The goal of this policy is to discourage very short stays while dampening the incentive to hold patients in the hospital as they near the threshold. At the same time, the new per-diem rates will be higher than the old rates, which may prompt LTCHs to keep some patients longer than they would have under the old system, particularly if they were very unlikely to remain in the hospital until the SSO threshold.

Panels (c) and (d) of Figure 8 show the predicted probability of discharge for any given day under this counterfactual compared to the baseline model. The policy is clearly effective at removing the spike in discharges at the SSO threshold. Comparing this counterfactual to the "lump-sum" counterfactual in panel (a), we see that, due to the offsetting effect of higher perdiem payments, far fewer discharges occur well in advance of the SSO threshold - discharges under this policy closely resemble the baseline discharge pattern ten days before and five days after the threshold. Rather than a general leftward shift in the distribution, we see a more localized shift in patients being discharged from just after the threshold to the days just before it. In this case, the impact of the policy is strongest for those patients likely to be discharged near the SSO threshold - for these patients, the looming lump-sum payment in the present scheme provides a strong incentive for LTCHs to hold them longer because the payoffs from delaying discharge are highest. Highlighting the policy's impact on strategic discharge behavior, patients that are still in the hospital three days before the magic day are now nine percent less likely to remain there until the SSO threshold than in the baseline model, and 17.2 percent less likely to be discharged in the three days after it. Overall, however, the impact of this payment scheme is more modest than the "lump-sum" scenario. Compared to the baseline model, the per-diem counterfactual has a 1.2-day shorter mean length of stay for the nine pooled DRGs, a three percent decrease.

It is likely that removing the spike in discharges is good for patients who are being held in the hospital solely so the LTCH can secure a larger payout. Nevertheless, the new policy may have opposing effects on overall Medicare payments: although shorter stays yield savings, the increased

\footnotetext{
${ }^{35}$ See Medicare Payment Advisory Commission (2014), chapter 11.
} 
per-diem rate partially offsets them. Taking this into account, we find that the MedPAC proposal does offer considerable savings for Medicare, reducing payments by four percent. On average, the per-diem payment scheme saves about $\$ 500$ per hospital stay compared to the current policy, which would amount to an annual aggregate savings of $\$ 18.9$ million across our sample. Our estimate is the first we are aware of in the literature that quantifies the effects of MedPAC's proposed policy change.

Finally, panels (e) and (f) of Figure 8 show the simulated discharge probabilities for a payment system based on reported costs. In this counterfactual, we construct a set of alternative payments equal to each patient's estimated daily cost plus five percent, referring to it as the "cost-plus" counterfactual and presenting it in panel (b) of Figure A4 in Online Appendix E. This counterfactual also successfully removes the spike in discharges, but does so by shifting discharges later. Overall, in the cost-plus counterfactual 79 percent of patients are held past the SSO threshold, which is similar to the baseline model. Focusing only on patients remaining in the hospital until at least three days prior to the magic day, however, yields an important insight. Of these patients, many fewer are discharged during the three days following the magic day (12 percent instead of 29 percent). As a result, the average length of stay under the counterfactual is five days longer than in the baseline. Implementing this policy would cause a 30 percent increase in payments to LTCHs, due to both longer stays and more-lucrative payments for long-staying patients.

As changes to the LTCH payment policy affect lengths of stay, they will also have consequences for patients' well-being. As we showed in Section 5, longer stays result in worse health outcomes for patients, all else equal. We therefore use the IV probit model from above to simulate how changing the reimbursement scheme will affect patient outcomes, with the results appearing in Table 9. Not only would dampening the incentive to strategically discharge patients reduce the average length of stay at LTCHs, it would also substantially reduce the likelihood of patients contracting HACs, being transferred back to an acute-care hospital, or dying at the LTCH. For example, we find that if MedPAC implemented the per-diem reimbursement policy, it would reduce the probability of patients contracting HACs by 4.9 percent and inpatient mortality by 2.0 percent, in addition to reducing the direct reimbursements to LTCHs by nearly $\$ 20$ million per year. Conversely, as the cost-plus reimbursement scheme would increase the average length of stay, it would also increase the risk of numerous adverse events, as shown in the final column of Table 9 .

Because adverse events have associated monetary and non-pecuniary costs, the impact of shorter stays on the direct health-care costs we estimated above are likely lower bounds. For example, if changing the reimbursement scheme to the per-diem policy reduces a patient's length of stay, and consequently also reduces the risk that she suffers an adverse event such as a pressure ulcer, catheter infection, or fall, the monetary savings we estimated above are conservative. 
Table 9: Counterfactual Outcomes II

\begin{tabular}{|c|c|c|c|c|}
\hline & Baseline model & $\begin{array}{c}\text { Counter. 1: } \\
\alpha=0\end{array}$ & $\begin{array}{l}\text { Counter. 2: } \\
\text { Per-diem }\end{array}$ & $\begin{array}{c}\text { Counter. 3: } \\
\text { Cost-plus }\end{array}$ \\
\hline & \multicolumn{4}{|c|}{ Mean probability of outcome } \\
\hline $\mathbb{P}($ Any $\mathrm{HAC})$ & 0.307 & 0.226 & 0.292 & 0.348 \\
\hline $\mathbb{P}($ Pressure Ulcer $)$ & 0.359 & 0.246 & 0.337 & 0.421 \\
\hline $\mathbb{P}($ Fall or trauma $)$ & 0.013 & 0.011 & 0.012 & 0.013 \\
\hline $\mathbb{P}$ (Catheter Infection) & 0.022 & 0.017 & 0.021 & 0.025 \\
\hline $\mathbb{P}($ Discharge to death $)$ & 0.181 & 0.162 & 0.177 & 0.186 \\
\hline $\mathbb{P}($ Discharge to death or hospital $)$ & 0.306 & 0.268 & 0.299 & 0.319 \\
\hline \multirow[t]{2}{*}{$\mathbb{P}($ Discharge to home $)$} & 0.350 & 0.432 & 0.365 & 0.328 \\
\hline & \multicolumn{4}{|c|}{ Percent change relative to baseline ${ }^{1}$} \\
\hline $\mathbb{P}($ Any HAC $)$ & & -26.2 & -4.9 & 13.6 \\
\hline $\mathbb{P}($ Pressure Ulcer $)$ & & -31.4 & -6.0 & 17.4 \\
\hline $\mathbb{P}($ Fall or trauma $)$ & & -11.7 & -2.1 & 5.3 \\
\hline $\mathbb{P}$ (Catheter Infection) & & -24.8 & -4.6 & 9.9 \\
\hline $\mathbb{P}($ Discharge to death $)$ & & -10.6 & -2.0 & 3.1 \\
\hline $\mathbb{P}($ Discharge to death or hospital $)$ & & -12.2 & -2.2 & 4.5 \\
\hline $\mathbb{P}($ Discharge to home $)$ & & 23.5 & 4.1 & -6.2 \\
\hline
\end{tabular}

Note: Means of simulated probabilities displayed.

${ }^{1}$ Percent change relative to baseline defined as: $\frac{\mathbb{P}_{\text {counterfactual }} \text { (outcome) }-\mathbb{P}_{\text {baseline }} \text { (outcome) }}{\mathbb{P}_{\text {baseline }}(\text { outcome })} * 100$.

Although a full accounting of these cost savings is beyond the scope of our current paper, we can provide a rough approximation using CMS cost estimates for HACs ${ }^{36}$ With the additional cost of a pressure ulcer estimated to be $\$ 17,000$, a catheter infection $\$ 13,800$, and a fall $\$ 7,234$, our simulation of the MedPAC per-diem reimbursement scheme suggests that Medicare would save an extra $\$ 14.9$ million per year, or 6 percent, as the earlier discharges under this payment policy would result in fewer HACs 37

\section{Conclusion}

Our paper shows that Medicare's prospective payment system for long-term care hospitals influences hospitals' discharge decisions. Because the current reimbursement formula provides a large lump-sum payment for patients who stay past a certain threshold, LTCHs respond to these financial incentives by holding patients until right after they reach this point. Our findings suggest that, on average, LTCHs keep patients too long due to this payment scheme, resulting in needless costs for Medicare and a greater risk of adverse events for patients.

\footnotetext{
${ }^{36}$ See https://www.ahrq.gov/sites/default/files/wysiwyg/professionals/quality-patient-safety/ pfp/interimhacrate2013.pdf.

${ }^{3 \top}$ Calculation based on simulated discharge distribution and HAC probit estimation. Full details available upon request.
} 
Our descriptive evidence documents strategic discharging by LTCHs. For the most common DRG, a patient's probability of being discharged increases approximately eightfold as she moves to the magic day from the day right before it. We can cleanly identify this as deliberate manipulation by LTCHs - rather than coincidental timing — by exploiting changes in the SSO thresholds within a DRG over time along with differences in thresholds across DRGs.

We also consider several nuances of the LTCH market. Consistent with reports from industry insiders, we find that for-profit LTCHs are much more likely to discharge patients immediately after they cross the SSO threshold. The two largest chains, Select and Kindred, also appear to transfer their corporate strategy of manipulating discharges to the LTCHs they acquire. We further find that LTCHs co-located with general acute-care hospitals are more likely to strategically discharge patients, perhaps because they can easily transfer patients across floors to secure larger payments from Medicare.

In addition, we also show that strategic discharging by LTCHs harms patients. We estimate that each additional day a patient is held unnecessarily in the hospital — identified here by variation in the financial incentives faced by LTCHs - substantially increases the risk that she acquires costly conditions like pressure ulcers or catheter infections, as well as increases the risk of dying in the hospital.

Finally, our dynamic structural model of LTCHs' discharge behavior allows us to evaluate MedPAC's recently proposed changes to the reimbursement formula that would reduce the payment penalty for patients discharged before reaching the SSO threshold. We show that removing the sharp jump in payments associated with the SSO threshold would save over $\$ 18.9$ million each year for the nine most common DRGs as LTCHs respond to the new policy by discharging patients sooner. In addition to these financial savings for Medicare, earlier discharges would also improve patient welfare by reducing the risk of adverse events and excess mortality.

\section{References}

Altman, S. H. (2012), 'The lessons of medicare's prospective payment system show hat the bundled payment program faces challenges', Health Affairs 31(9), 1923-1930.

Berenson, A. (2/9/2010), 'Long-term care hospitals face little scrutiny', New York Times .

Chakravarty, S., Gaynor, M., Klepper, S. \& Vogt, W. B. (2006), 'Does the profit motive make jack nimble? ownership form and the evolution of the us hospital industry', Health Economics 15(4), 345-361.

Dafny, L. S. (2005), 'How do hospitals respond to price changes?', American Economic Review pp. 1525-1547.

Decarolis, F. (2015), 'Medicare part d: Are insurers gaming the low income subsidy design?', American Economic Review 105(4), 1547-1580. 
Dranove, D. (1988), 'Pricing by non-profit institutions: the case of hospital cost-shifting', Journal of Health Economics 7(1), 47-57.

Einav, L., Finkelstein, A. \& Mahoney, N. (2016), 'Provider incentives and health care costs: Evidence from long-term care hospitals', Working Paper .

Einav, L., Finkelstein, A., Ryan, S. P., Schrimpf, P. \& Cullen, M. R. (2013), 'Selection on moral hazard in health insurance', American Economic Review 103(1), 178-219.

Grieco, P. L. E. \& McDevitt, R. C. (forthcoming), 'Productivity and quality in health care: Evidence from the dialysis industry', Review of Economic Studies .

Ho, K. \& Pakes, A. (2014), 'Hospital choices, hospital prices and financial incentives to physicians', American Economic Review 104(12), 3841-3884.

Kahn, J. M., Barnato, A. E., Lave, J. R., Pike, F., Weissfeld, L. A., Le, T. Q. \& Angus, D. C. (2015), 'A comparison of free-standing versus co-located long-term acute care hospitals', PloS one 10(10), e0139742.

Kim, Y. S., Kleerup, E. C., Ganz, P. A., Ponce, N. A., Lorenz, K. A. \& Needleman, J. (2015), 'Medicare payment policy creates incentives for long-term care hospitals to time discharges for maximum reimbursement', Health Affairs 34(6), 907-915.

Manning, W., Newhouse, J., Duan, N., Keeler, E., Leibowitz, A. \& Marquis, S. (1987), 'Health insurance and the demand for medical care: Evidence from a randomized experiment', American Economic Review 77(3), 251-277.

Medicare Payment Advisory Commission (2014), Report to the Congress: Medicare Payment Policy, Medicare Payment Advisory Commission.

Newhouse, J. (1993), Free for All? Lessons from the RAND Health Insurance Experiment, Harvard University Press.

Rust, J. (1987), 'Optimal replacement of gmc bus engines: an empirical model of harold zurcher', Econometrica pp. 999-1033.

Schlesinger, M. \& Gray, B. H. (2006), 'How nonprofits matter in american medicine, and what to do about it', Health Affairs 25(4), W287-W303.

Silverman, E. \& Skinner, J. (2004), 'Medicare upcoding and hospital ownership', Journal of Health Economics 23(2), 369-389.

Weaver, C., Mathews, A. W. \& McGinty, T. (2/17/2015), 'Hospital discharges rise at lucrative times', Wall Street Journal .

Wilson, N. (2013), 'For-profit status \& industry evolution in health care market: Evidence from the dialysis industry', Federal Trade Commission, Bureau of Economics Working Paper (314). 


\section{Online Appendix — Not For Publication}

\section{A Complete Summary Statistics}

Table A1: Summary Statistics for All Patients (2004-2013)

\begin{tabular}{|c|c|c|}
\hline Variable & Mean & Std. Dev. \\
\hline Length of Stay & 28.766 & 41.844 \\
\hline Released on or after magic day & 0.681 & 0.466 \\
\hline Total Payment $(\$)$ & $31,933.43$ & $24,332.54$ \\
\hline Amount Paid by Medicare $(\$)$ & $31,814.61$ & $26,883.69$ \\
\hline Estimated Costs $(\$)$ & $37,578.69$ & $37,022.04$ \\
\hline Portion Discharged Alive & 0.861 & 0.346 \\
\hline Portion Discharged Dead & 0.139 & 0.346 \\
\hline Portion Discharged to Home Care & 0.34 & 0.474 \\
\hline Portion Discharged to Hospital & 0.123 & 0.329 \\
\hline Portion Discharged to Nursing Facility & 0.391 & 0.488 \\
\hline Admission Type: Emergency & 0.011 & 0.104 \\
\hline Admission Type: Urgent & 0.198 & 0.398 \\
\hline Admission Type: Elective & 0.785 & 0.411 \\
\hline Admission Type: Other & 0.006 & 0.079 \\
\hline Admission Source: Community & 0.186 & 0.389 \\
\hline Admission Source: Nursing Facility & 0.025 & 0.155 \\
\hline Admission Source: General Hospital & 0.777 & 0.416 \\
\hline Admission Source: Other Source & 0.007 & 0.085 \\
\hline Male & 0.484 & 0.5 \\
\hline White & 0.729 & 0.445 \\
\hline Black & 0.202 & 0.401 \\
\hline Asian & 0.012 & 0.111 \\
\hline Hispanic & 0.033 & 0.18 \\
\hline Age less than 25 & 0.001 & 0.038 \\
\hline Ave between 25 and 44 & 0.039 & 0.193 \\
\hline Age between 45 and 64 & 0.191 & 0.393 \\
\hline Age between 65 and 74 & 0.305 & 0.46 \\
\hline Age between 75 and 84 & 0.301 & 0.459 \\
\hline Age over 85 & 0.164 & 0.37 \\
\hline$N=1,452,287$ & & \\
\hline
\end{tabular}


Table A2: Summary Statistics for DRG 207 Patients (2004-2013)

\begin{tabular}{lcc}
\hline \multicolumn{1}{c}{ Variable } & Mean & Std. Dev. \\
\hline Length of Stay & 38.06 & 40.24 \\
Released on or after magic day & 0.672 & 0.47 \\
Total Payment (\$) & $57,609.66$ & $33,061.67$ \\
Amount Paid by Medicare $(\$)$ & $57,536.17$ & $37,143.23$ \\
Estimated Costs $\$$ ) & $67,061.07$ & $51,780.64$ \\
Portion Discharged Alive & 0.736 & 0.441 \\
Portion Discharged Dead & 0.264 & 0.441 \\
Portion Discharged to Home Care & 0.132 & 0.338 \\
Portion Discharged to Hospital & 0.166 & 0.372 \\
Portion Discharged to Nursing Facility & 0.437 & 0.496 \\
Admission Type: Emergency & 0.011 & 0.105 \\
Admission Type: Urgent & 0.202 & 0.402 \\
Admission Type: Elective & 0.781 & 0.414 \\
Admission Type: Other & 0.006 & 0.076 \\
Admission Source: Community & 0.122 & 0.327 \\
Admission Source: Nursing Facility & 0.013 & 0.115 \\
Admission Source: General Hospital & 0.857 & 0.35 \\
Admission Source: Other Source & 0.003 & 0.054 \\
Male & 0.502 & 0.5 \\
White & 0.745 & 0.436 \\
Black & 0.192 & 0.394 \\
Asian & 0.015 & 0.122 \\
Hispanic & 0.024 & 0.154 \\
Age less than 25 & 0.002 & 0.04 \\
Ave between 25 and 44 & 0.03 & 0.17 \\
Age between 45 and 64 & 0.187 & 0.39 \\
Age between 65 and 74 & 0.355 & 0.478 \\
Age between 75 and 84 & 0.32 & 0.466 \\
Age over 85 & 0.107 & 0.309 \\
\hline$N=170,365$ & & \\
\hline & & \\
& &
\end{tabular}


Table A3: Share of discharges on the magic day and the preceding day

\begin{tabular}{lcccccc}
\hline Comparison Set & $\begin{array}{c}\text { Day before } \\
\text { magic day }\end{array}$ & Magic Day & Ratio & P-value $^{1}$ & $\begin{array}{c}\text { Diff-in- } \\
\text { Ratios }\end{array}$ & P-value $^{2}$ \\
\hline Home & 0.017 & 0.103 & 6.06 & 0.000 & & \\
Nursing Facility & 0.009 & 0.076 & 8.44 & 0.000 & -2.38 & 0.010 \\
Acute Care Hospital & 0.016 & 0.024 & 1.5 & 0.001 & 4.56 & 0.000 \\
Death & 0.018 & 0.019 & 1.06 & 0.517 & 5.01 & 0.000 \\
\hline 2004 & 0.016 & 0.036 & 2.25 & 0.000 & \multirow{2}{*}{3.19} & \multirow{2}{*}{0.000} \\
2013 & 0.016 & 0.087 & 5.44 & 0.000 & & \\
\hline For-profit & 0.010 & 0.092 & 9.20 & 0.000 & \multirow{2}{*}{4.60} & \multirow{2}{*}{0.000} \\
Non-profit & 0.015 & 0.069 & 4.60 & 0.000 & & \\
\hline Select or Kindred & 0.010 & 0.089 & 8.91 & 0.000 & \multirow{2}{*}{3.29} & \multirow{2}{*}{0.000} \\
Other & 0.013 & 0.073 & 5.62 & 0.000 & & \\
\hline Before Acquisition & 0.014 & 0.087 & 6.21 & 0.000 & \multirow{2}{*}{8.93} & \multirow{2}{*}{0.000} \\
After Acquisition & 0.007 & 0.106 & 15.14 & 0.000 & & \multirow{2}{*}{0.074} \\
\hline Co-located & 0.012 & 0.101 & 8.42 & 0.000 & \multirow{2}{*}{1.78} & \\
Not Co-located & 0.011 & 0.073 & 6.64 & 0.000 & & \\
\hline
\end{tabular}

Note: P-values from Wald tests of nonlinear hypotheses. Difference-in-ratios for nursing facility, acute-care hospital, and death discharges are all with respect to home discharges. Except for the discharge destination rows, the statistics include hospital stays ending in discharge to home or nursing facility care.

${ }^{1} \mathrm{P}$-value under the null hypothesis that the ratio is equal to one.

${ }^{2} \mathrm{P}$-value under the null hypothesis that the difference-in-ratios equals zero. 
Table A4: First Stage of Patient Outcome Analysis

\begin{tabular}{|c|c|c|}
\hline Dependent variable: Days in hospital/LOS & $(1)$ & $(2)$ \\
\hline SSO Threshold & $\begin{array}{l}0.58^{* * *} \\
(0.044)\end{array}$ & $\begin{array}{c}0.56^{* * *} \\
(0.044)\end{array}$ \\
\hline Black & $\begin{array}{l}1.06^{* * *} \\
(0.110)\end{array}$ & $\begin{array}{l}1.36^{* * *} \\
(0.073)\end{array}$ \\
\hline Over 65 & $\begin{array}{c}-0.30^{* * *} \\
(0.072)\end{array}$ & $\begin{array}{c}-0.31^{* * *} \\
(0.068)\end{array}$ \\
\hline \multicolumn{3}{|l|}{ LTCH Type } \\
\hline For-profit, standalone & $\begin{array}{l}1.98^{* * *} \\
(0.158)\end{array}$ & \\
\hline Non-profit, HWH & $\begin{array}{l}0.50^{* * *} \\
(0.252)\end{array}$ & \\
\hline Non-profit, standalone & $\begin{array}{l}2.79^{* * *} \\
(0.272)\end{array}$ & \\
\hline Year FE & $\mathrm{X}$ & $\mathrm{X}$ \\
\hline DRG FE & $\mathrm{X}$ & $\mathrm{X}$ \\
\hline Hospital FE & & $\mathrm{X}$ \\
\hline$N$ & 537,083 & 540,986 \\
\hline $\mathrm{R}^{2}$ & 0.132 & 0.146 \\
\hline
\end{tabular}

Note: Standard errors (in parentheses) are clustered at the hospital $\times$ DRG level. The sample includes the nine most common DRGs for years from 2004 to 2013. The reference LTCH type is for-profit HWH. 


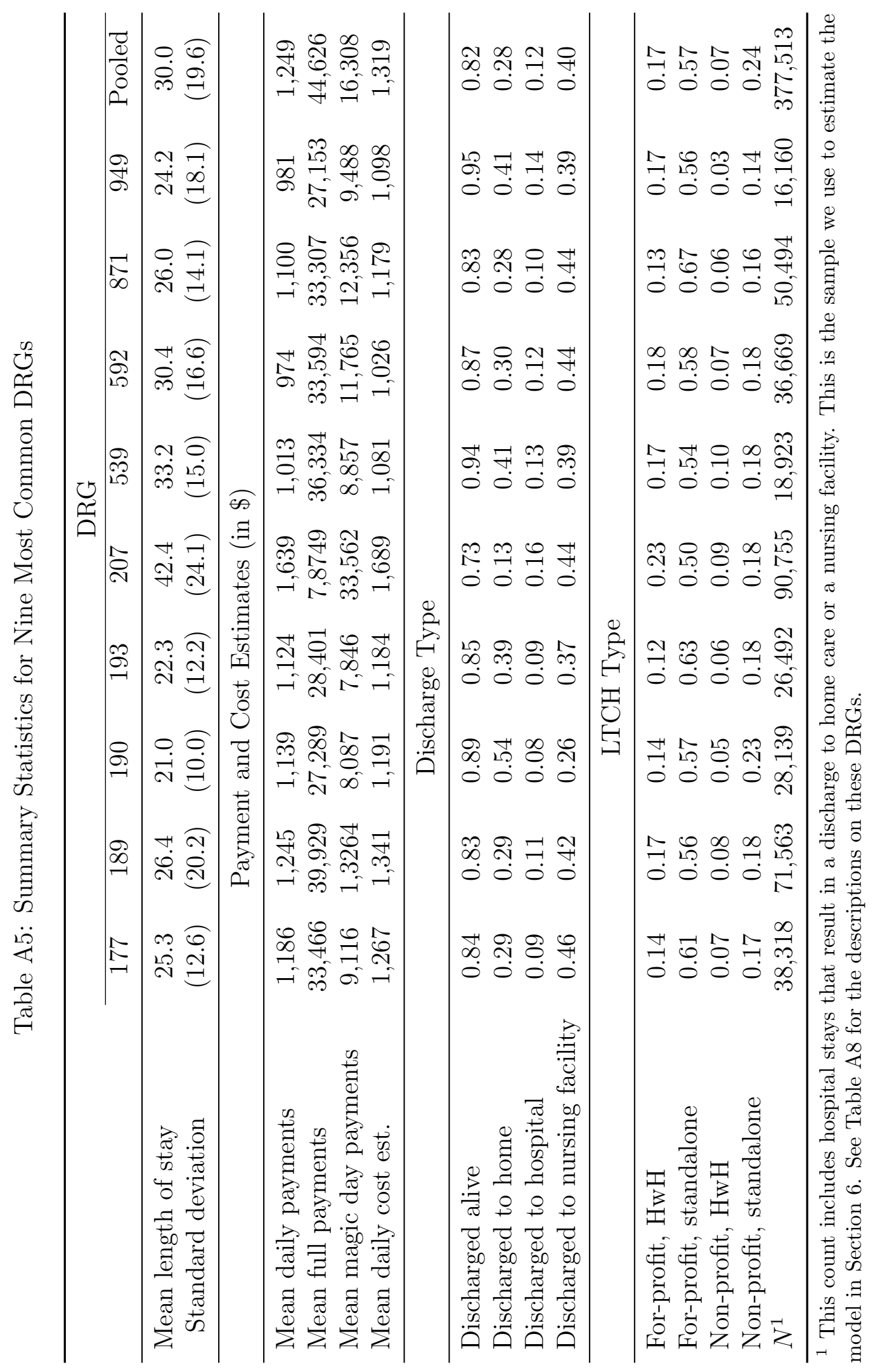


Table A6: Per-diem estimates (in \$)

\begin{tabular}{|c|c|c|c|c|}
\hline & \multicolumn{3}{|c|}{25 th } & \multirow{2}{*}{$\begin{array}{c}75 \text { th } \\
\text { Percentile }\end{array}$} \\
\hline & Mean & Percentile & Median & \\
\hline \multicolumn{5}{|c|}{ Panel A: Per-diem rate } \\
\hline Overall & 1,249 & 1,050 & 1,195 & 1,414 \\
\hline For-profit, $\mathrm{HwH}$ & 1,235 & 1,005 & 1,179 & 1,480 \\
\hline For-profit, standalone & 1,228 & 1,043 & 1,178 & 1,368 \\
\hline Non-profit, $\mathrm{HwH}$ & 1,280 & 1,055 & 1,220 & 1,503 \\
\hline Non-profit, standalone & 1,317 & 1,117 & 1,257 & 1,507 \\
\hline Select & 1,250 & 1,024 & 1,206 & 1,482 \\
\hline Kindred & 1,232 & 1,049 & 1,187 & 1,377 \\
\hline Other & 1,257 & 1,058 & 1,198 & 1,405 \\
\hline \multicolumn{5}{|c|}{ Panel B: Full LTCH PPS payment } \\
\hline Overall & 44,626 & 30,938 & 35,155 & 61,702 \\
\hline For-profit, HwH & 46,876 & 30,517 & 35,195 & 72,845 \\
\hline For-profit, standalone & 43,817 & 31,318 & 35,208 & 43,111 \\
\hline Non-profit, $\mathrm{HwH}$ & 44,177 & 33,746 & 33,746 & 68,396 \\
\hline Non-profit, standalone & 45,256 & 30,853 & 35,302 & 63,558 \\
\hline Select & 47,480 & 31,310 & 35,577 & 73,571 \\
\hline Kindred & 46,358 & 33,097 & 36,889 & 59,953 \\
\hline Other & 42,661 & 30,092 & 34,059 & 42,658 \\
\hline \multicolumn{5}{|c|}{ Panel C: Magic day payments } \\
\hline Overall & 16,308 & 8,742 & 12,450 & 22,710 \\
\hline For-profit, $\mathrm{HwH}$ & 17,763 & 8,965 & 13,529 & 29,478 \\
\hline For-profit, standalone & 16,351 & 9,209 & 12,630 & 20,749 \\
\hline Non-profit, $\mathrm{HwH}$ & 14,437 & 7,018 & 11,352 & 23,111 \\
\hline Non-profit, standalone & 15,536 & 7,918 & 11,127 & 24,193 \\
\hline Select & 18,114 & 9,592 & 13,742 & 30,162 \\
\hline Kindred & 18,448 & 10,666 & 14,591 & 25,715 \\
\hline Other & 14,555 & 7,763 & 11,234 & 18,895 \\
\hline$N=377,513$ & & & & \\
\hline
\end{tabular}


Table A7: Average daily cost estimates (in \$)

\begin{tabular}{lcccc}
\hline & Mean & $\begin{array}{c}\mathbf{2 5 t h} \\
\text { Percentile }\end{array}$ & Median & $\begin{array}{c}\text { 75th } \\
\text { Percentile }\end{array}$ \\
\hline Overall & 1,319 & 1,075 & 1,280 & 1,526 \\
\hline For-profit, HwH & 1,266 & 1,003 & 1,237 & 1,501 \\
For-profit, standalone & 1,300 & 1,078 & 1,267 & 1,488 \\
Non-profit, HwH & 1,398 & 1,100 & 1,365 & 1,640 \\
Non-profit, standalone & 1,401 & 1,135 & 1,372 & 1,631 \\
\hline Select & 1,279 & 1,028 & 1,267 & 1,497 \\
Kindred & 1,293 & 1,078 & 1,253 & 1,487 \\
Other & 1,348 & 1,089 & 1,301 & 1,558 \\
\hline$N=377,513$ & & & \\
\hline
\end{tabular}




\section{B Other DRGs}

While our paper at times focuses on DRG 207, in this appendix we extend the analysis to other DRGs, summarized above in Appendix A. Our structural estimation uses the nine most common DRGs in order to increase the variation in magic days in the data. Table A8 describes each of these DRGs. Figure A1 plots discharge patterns for the next three most common DRGs after DRG 207 in 2004 and 2013, along with their respective SSO thresholds. Figure A2 plots realized Medicare payments and discharge patterns that suggest other DRGs have similar discharge practices.

Table A8: DRG Descriptions

\begin{tabular}{ll}
\hline DRG & Description \\
\hline 177 & $\begin{array}{l}\text { Respiratory infections and inflammations with } \\
\text { major complicating conditions }\end{array}$ \\
189 & $\begin{array}{l}\text { Pulmonary edema and respiratory failure } \\
190\end{array}$ \\
& $\begin{array}{l}\text { Chronic obstructive pulmonary disease with major } \\
\text { complicating conditions }\end{array}$ \\
193 & $\begin{array}{l}\text { Simple pneumonia and pleurisy with major complicating } \\
\text { conditions }\end{array}$ \\
& $\begin{array}{l}\text { Respiratory system diagnosis with ventilator support of } \\
\text { over 96 hours }\end{array}$ \\
539 & Osteomyelitis with major complicating conditions \\
592 & Skin ulcers \\
871 & $\begin{array}{l}\text { Septicemia without mechanical ventilation of over } \\
96 \text { hours with major complicating conditions }\end{array}$ \\
& $\begin{array}{l}\text { Aftercare with complication conditions or major } \\
\text { complicating conditions }\end{array}$ \\
\hline
\end{tabular}



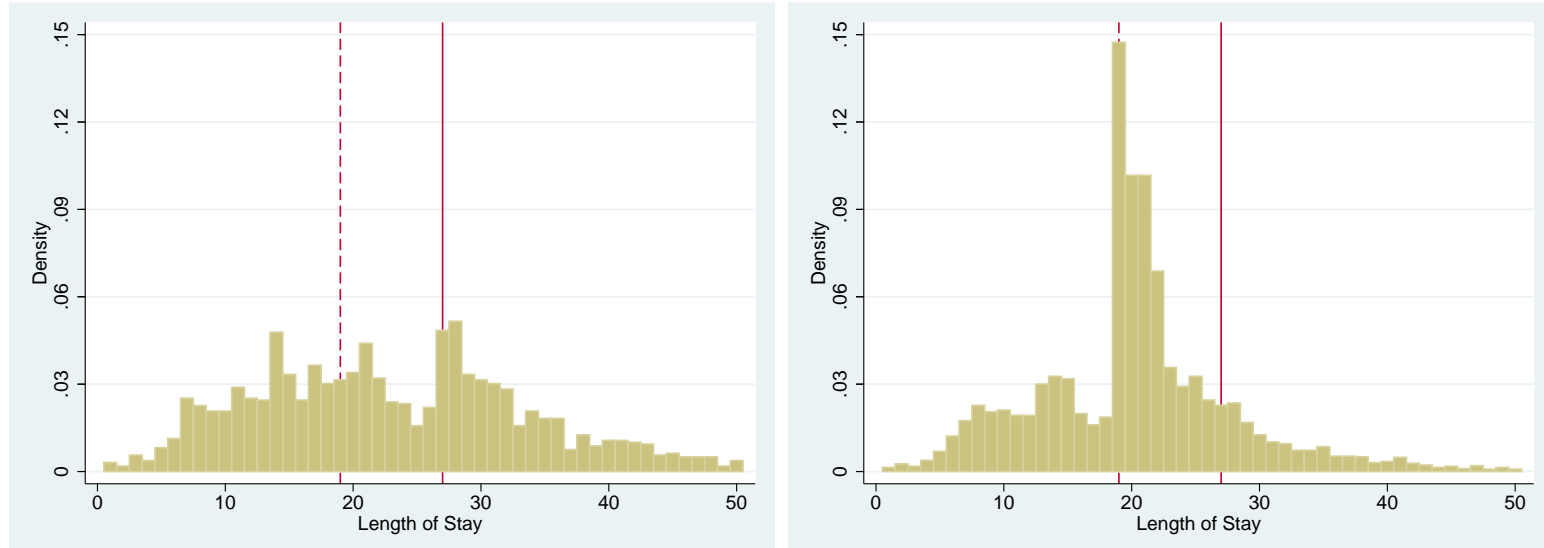

(a) Discharge practices for DRG 189 in 2004

(b) Discharge practices for DRG 189 in 2013
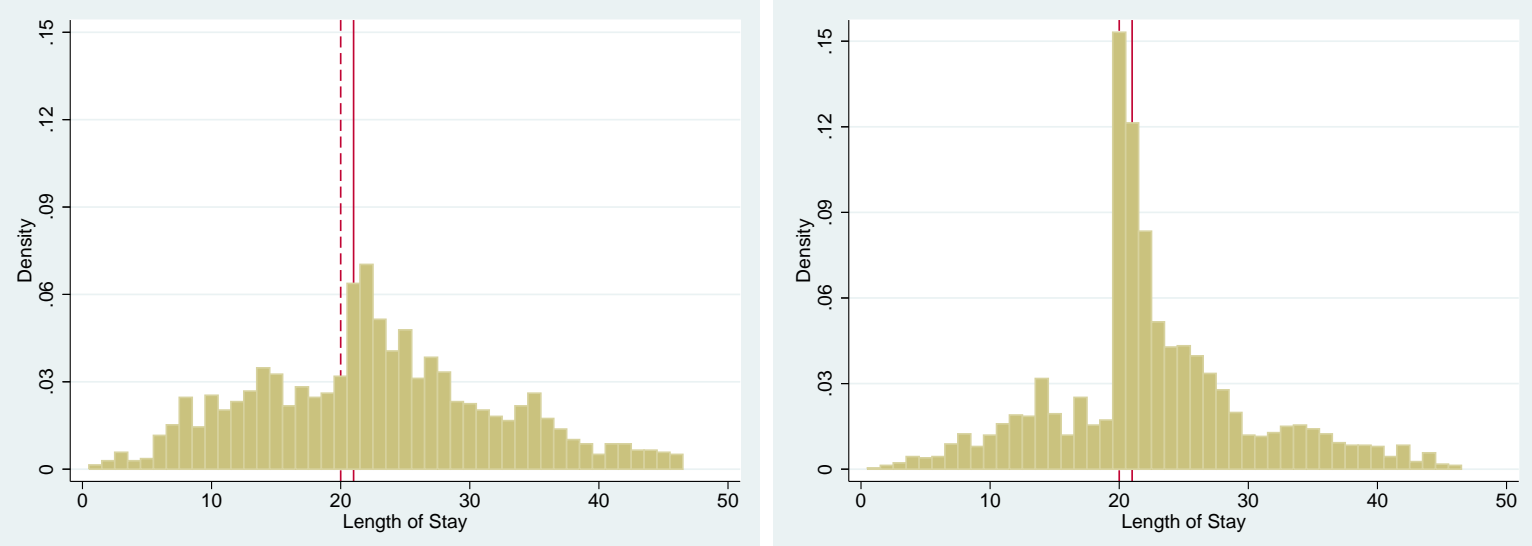

(c) Discharge practices for DRG 871 in 2004

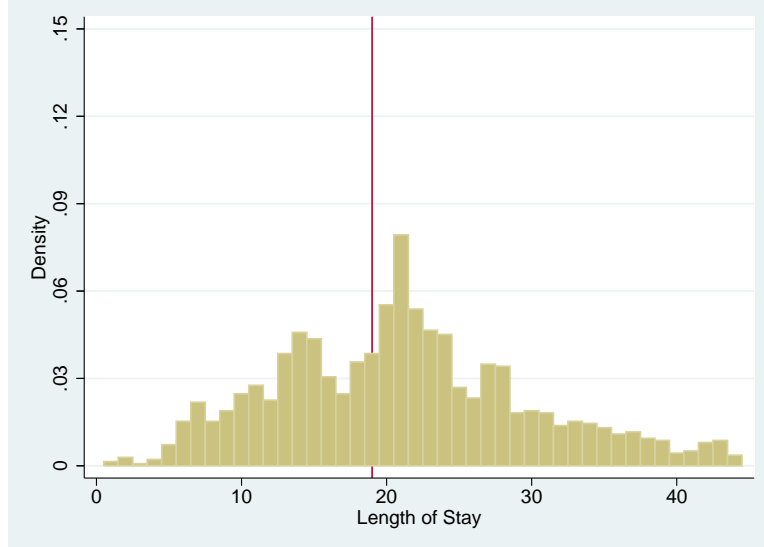

(d) Discharge practices for DRG 871 in 2013

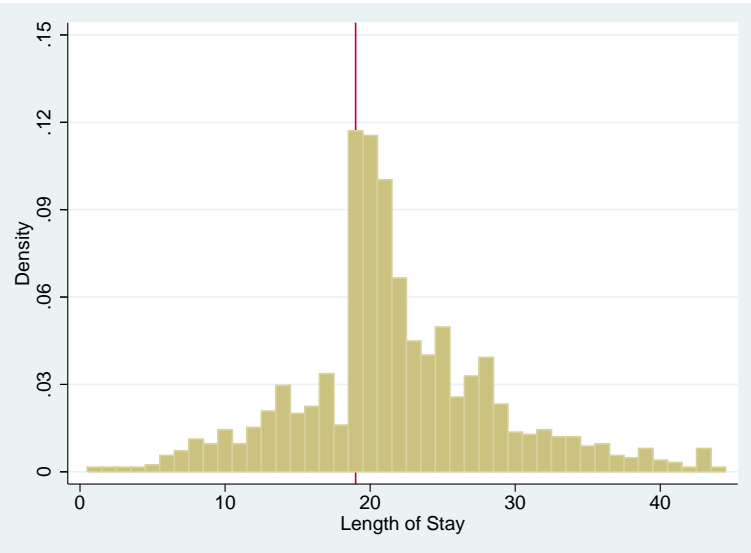

(e) Discharge practices for DRG 177 in 2004

(f) Discharge practices for DRG 177 in 2013

Figure A1: Discharge timing across DRGs and years 


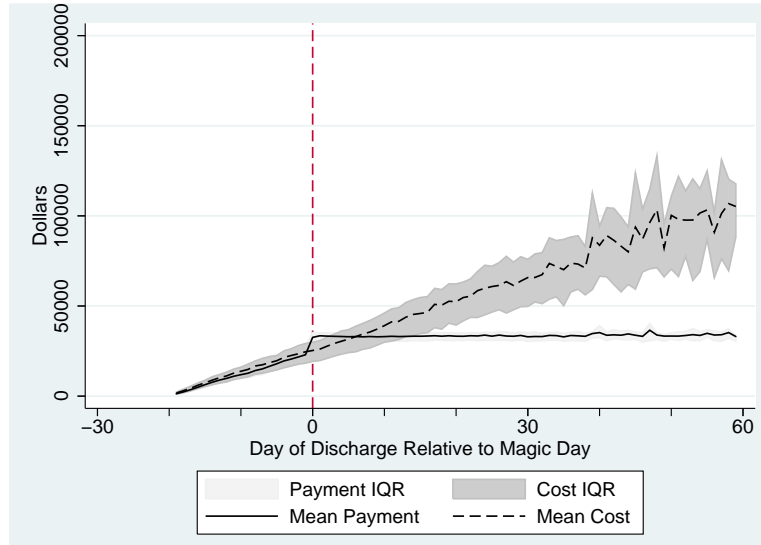

(a) Payoffs and Costs for DRG 177

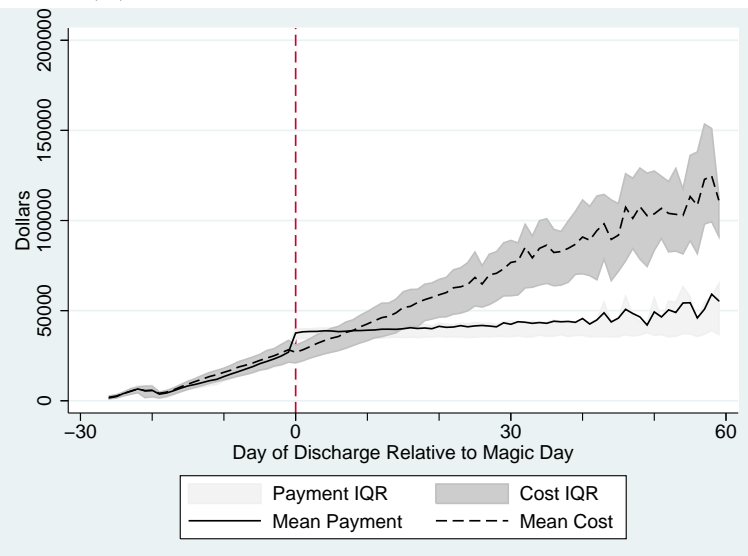

(c) Payoffs and Costs for DRG 189

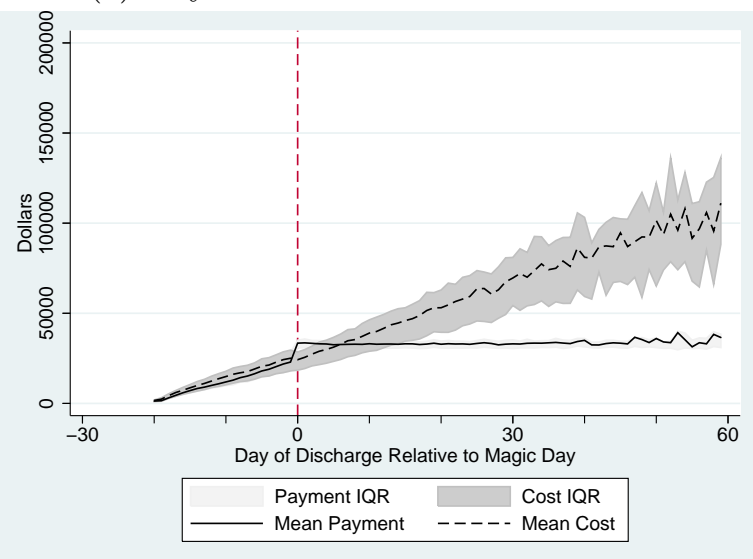

(e) Payoffs and Costs for DRG 871

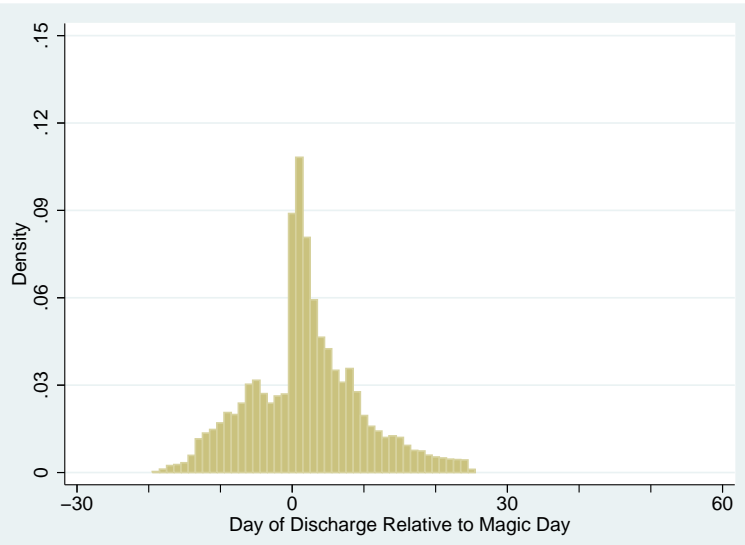

(b) Lengths of stay for DRG 177

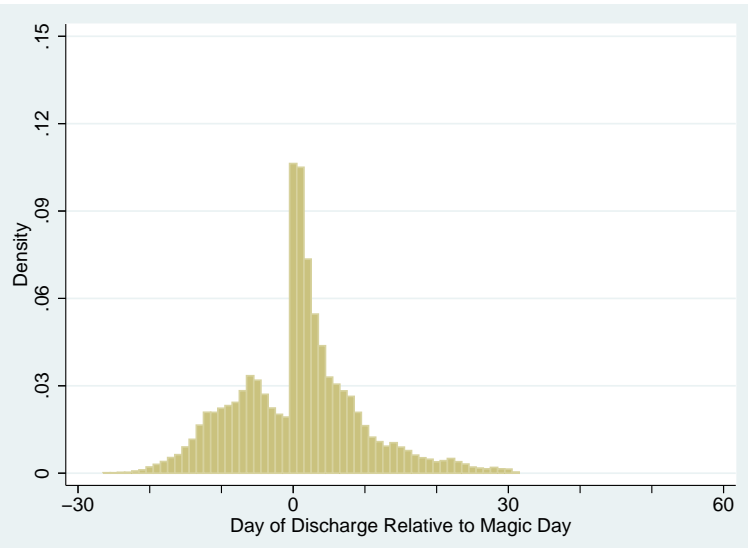

(d) Lengths of stay for DRG 189

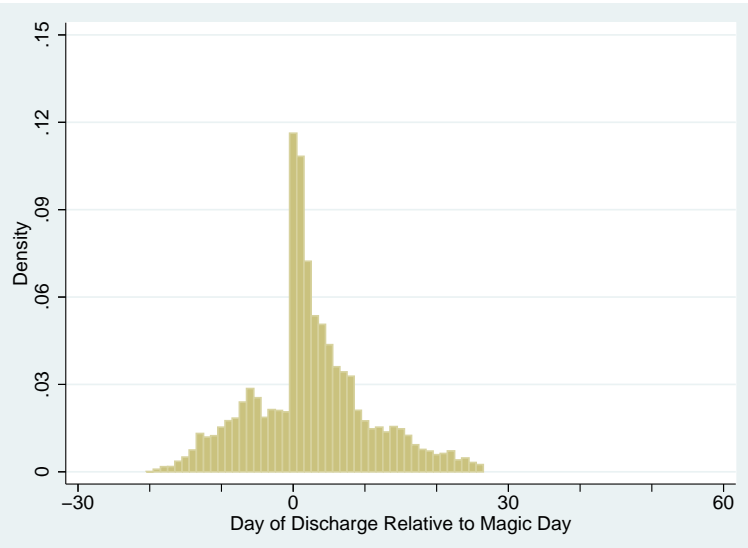

(f) Lengths of stay for DRG 871

Figure A2: Costs, payoffs and discharge patterns for other DRGs 


\section{Payment Policy Details \& Example}

Medicare calculates the PPS by starting with an LTCH Standard Federal Rate, or LTCH base rate, which was $\$ 39,794.95$ in FY2010. Two adjustments are then applied to this base rate. The first is a hospital wage index adjustment that incorporates geographic differences in costs due to health-sector wages. The second is a Medicare severity long-term care diagnosis related group (MT-LTC-DRG) adjustment. The MT-LTC-DRG weight adjusts the payment to account for patient diagnoses (principal and secondary), procedures, age, sex, and discharge status based on the expected relative costliness of patients in each group. The final adjusted amount is known as the full LTCH payment.

For short stays, Medicare pays LTCHs the least of the following:

1. The full MS-LTC-DRG payment, or

2. 100 percent of the cost of the case, or

3. 120 percent of the MS-LTC-DRG specific per-diem amount multiplied by the length of stay, or

4. A blend of the inpatient MS-DRG amount and 120 percent of the LTCH per-diem amount, where the portion coming from the LTCH per-diem amount increases with the length of stay.

Starting in calendar year 2013 there is also a "very short stay outlier" payment. Cases with stays less than or equal to the IPPS average length of stay are reimbursed at weakly lower rates than SSOs. These payments are set to the least of the four possibilities enumerated in the SSO case above but replace the blended case with just the inpatient MS-DRG amount ${ }^{38}$

\section{Full MS-LTC-DRG payment}

\section{Example of Full LTCH-PPS Payment in 2010, DRG 207}

LTCH Base Rate

Labor-related portion of base rate

Non-labor related portion of base rate

Labor-related portion adjusted for wage index (CBSA 16974)

Wage-adjusted LTCH Base Rate

MS-LTC-DRG 207 Relative Weight

Total Adjusted Federal Prospective Payment
$\$ 39,794.95$

$\$ 39,794.95 \times 0.75779=\$ 30,156.22$

$\$ 39,794.95 \times 0.24221=\$ 9,638.73$

$\$ 30,156.22 \times 1.0471=\$ 31,576.57$

For more examples of computing full LTCH-PPS payments, see CMS document: https://www.cms.gov/Medicare/Medicare-Fee-for-Service-Payment/LongTermCareHospitalPPS/ Downloads/LTCH_sso_ex_2007and2008.zip.

\footnotetext{
${ }^{38}$ To discourage LTCHs from avoiding extremely high-cost patients, Medicare will share costs beyond what are reimbursed through the standard long-term care payment. In 2015, for example, if the costs incurred by an LTCH were more than the full long-term care payment plus $\$ 14,972$, then Medicare will pay 80 percent of the difference. According to our data, this happens in about 10 percent of long-term stays for DRG 207.
} 


\section{0 percent of cost of case}

$$
\text { cost of case }=(\text { covered charges }) \times(\text { cost-to-charge ratio })
$$

The hospital-specific cost-to-charge ratio is just what it sounds like. It is calculated for each hospital using cost data from the most recent cost report submitted from that hospital. Hospital CCR has two parts: operative CCR (total Medicare operating costs / total Medicare operating charges) and capital CCR (total Medicare capital costs / total Medicare capital charges). The CCR for each year is published in the LTCH Impact Files in August before the year begins and is based on most recent historical Medicare cost reports which are required on an annual basis.

$$
\$ 45,501.00 \times 0.311=\$ 14,150.81=\text { Estimated Cost }
$$

${ }^{*}$ Assumes covered charges $=\$ 45,501.00$ and hospital $\mathrm{CCR}=0.311$.

\section{0 percent of per-diem amount}

*LTC-DRG average length of stay: 26.6 days. This case assumes an 8 day length of stay.

MS-LTC-DRG per diem = Full LTC-DRG Payment / Average Length of Stay of the LTC-DRG

$$
\begin{aligned}
& =\$ 45,060.70 / 26.6 \text { days } \\
& =\$ 1,698.34 \text { per day }
\end{aligned}
$$

120 percent of per-diem amount $=\$ 1,698.34 \times 8$ days $\times 1.2$

$$
=\$ 16,304.06
$$

\section{Blend Alternative}

Computing the IPPS payment is considerably more involved, so for this example we simply assume it is $\$ 24,442.17$. The portion coming from the 120 percent of LTCH per diem is: $\frac{\text { length of stay }}{\text { SSO threshold }}=\frac{8}{22.2}=0.36$. The rest comes from the inpatient comparable per-diem amount that, after a complex series of calculations, is $\$ 24,442.17$. The blended amount is then:

$$
0.36 \times \$ 16,304.06+0.64 \times \$ 24442.17=\$ 21,512.45
$$

Since the "100 percent of cost" amount is the least, the law indicates that it is the will be paid out. 


\section{Probit Model: Coefficient Estimates and other DRGs}

Table A9 contains the estimated coefficients from the probit model for DRG 207. Table A10 presents the estimated marginal effects of the baseline probit model for other DRGs. Table A11 shows (a sample of) the estimated probit coefficients for the interacted models for DRG 207.

Table A9: Probit Estimates for DRG 207

\begin{tabular}{lcc}
\hline & Coefficients & Std. Err. \\
\hline \multicolumn{3}{c}{ Days relative to magic day $(\lambda \mathrm{s})$} \\
\hline-14 & 0 & (Omitted group) \\
-13 & -0.021 & $(0.022)$ \\
-12 & $0.068^{* *}$ & $(0.026)$ \\
-11 & $0.103^{* * *}$ & $(0.029)$ \\
-9 & $0.193^{* * *}$ & $(0.032)$ \\
-8 & $0.333^{* * *}$ & $(0.036)$ \\
-7 & $0.446^{* * *}$ & $(0.041)$ \\
-6 & $0.497^{* * *}$ & $(0.046)$ \\
-5 & $0.482^{* * *}$ & $(0.051)$ \\
-4 & $0.486^{* * *}$ & $(0.053)$ \\
-3 & $0.514^{* * *}$ & $(0.062)$ \\
-2 & $0.522^{* * *}$ & $(0.066)$ \\
-1 & $0.568^{* * *}$ & $(0.070)$ \\
0 & $0.665^{* * *}$ & $(0.075)$ \\
1 & $1.601^{* * *}$ & $(0.080)$ \\
2 & $1.470^{* * *}$ & $(0.087)$ \\
3 & $1.414^{* * *}$ & $(0.089)$ \\
4 & $1.413^{* * *}$ & $(0.094)$ \\
5 & $1.430^{* * *}$ & $(0.099)$ \\
6 & $1.566^{* * *}$ & $(0.104)$ \\
7 & $1.659^{* * *}$ & $(0.105)$ \\
8 & $1.608^{* * *}$ & $(0.109)$ \\
9 & $1.538^{* * *}$ & $(0.113)$ \\
10 & $1.495^{* * *}$ & $(0.117)$ \\
12 & $1.496^{* * *}$ & $(0.121)$ \\
13 & $1.518^{* * *}$ & $(0.125)$ \\
\hline & $1.596^{* * *}$ & $(0.129)$ \\
\hline & $1.693^{* * *}$ & $(0.132)$ \\
\hline & $1.646^{* * *}$ & $(0.135)$ \\
\hline & $-0.048^{* * *}$ & $(0.009)$ \\
\hline & $-1.893^{* * *}$ & $(0.1007)$ \\
\hline & &
\end{tabular}


Table A10: Marginal Effects on Probability of Discharge Other DRGs

\begin{tabular}{|c|c|c|c|}
\hline $\begin{array}{l}\text { Day of } \\
\text { stay }(t)\end{array}$ & $\begin{array}{c}\text { Probability of Discharge } \\
\text { on Magic Day }{ }^{1}\end{array}$ & $\begin{array}{c}\text { Probability of Discharge } \\
\text { on Day Preceding Magic Day }\end{array}$ & $\begin{array}{l}\text { Hazard } \\
\text { Ratio }^{3}\end{array}$ \\
\hline \multicolumn{4}{|c|}{ DRG 189} \\
\hline \multirow[t]{2}{*}{19} & $11.02^{* * *}$ & $1.73^{* * *}$ & $6.39^{* * *}$ \\
\hline & $(0.358)$ & $(0.074)$ & [204.9] \\
\hline \multirow[t]{2}{*}{20} & $11.40^{* * *}$ & $1.81^{* * *}$ & $6.29^{* * *}$ \\
\hline & $(0.353)$ & $(0.080)$ & [203.3] \\
\hline \multirow[t]{2}{*}{21} & $11.77^{* * *}$ & $1.90^{* * *}$ & $6.20^{* * *}$ \\
\hline & $(0.352)$ & $(0.086)$ & [201.3] \\
\hline \multirow[t]{2}{*}{22} & $12.11^{* * *}$ & $1.98^{* * *}$ & $6.12^{* * *}$ \\
\hline & $(0.354)$ & $(0.093)$ & [199.0] \\
\hline \multirow[t]{2}{*}{23} & $12.23^{* * *}$ & $2.06^{* * *}$ & $6.05^{* * *}$ \\
\hline & $(0.358)$ & $(0.101)$ & [196.5] \\
\hline \multirow[t]{2}{*}{24} & $12.72^{* * *}$ & $2.13^{* * *}$ & $5.98^{* * *}$ \\
\hline & $(0.364)$ & $(0.109)$ & [193.8] \\
\hline \multirow[t]{2}{*}{25} & $12.99^{* * *}$ & $2.19^{* * *}$ & $5.92^{* * *}$ \\
\hline & $(0.372)$ & $(0.117)$ & [191.0] \\
\hline \multirow[t]{2}{*}{26} & $13.23^{* * *}$ & $2.25^{* * *}$ & $5.87^{* * *}$ \\
\hline & $(0.382)$ & $(0.125)$ & [188.0] \\
\hline \multirow[t]{2}{*}{27} & $13.43^{* * *}$ & $2.30^{* * *}$ & $5.83^{* * *}$ \\
\hline & $(0.393)$ & $(0.134)$ & [184.9] \\
\hline \multicolumn{4}{|c|}{ DRG 871} \\
\hline \multirow[t]{2}{*}{19} & $11.80^{* * *}$ & $1.72^{* * *}$ & $6.87^{* * *}$ \\
\hline & $(0.716)$ & $(0.088)$ & [115.7] \\
\hline \multirow[t]{2}{*}{20} & $13.02^{* * *}$ & $1.99^{* * *}$ & $6.55^{* * *}$ \\
\hline & $(0.619)$ & $(0.119)$ & [103.7] \\
\hline \multirow[t]{2}{*}{21} & $14.22^{* * *}$ & $2.27^{* * *}$ & $6.27^{* * *}$ \\
\hline & $(0.629)$ & $(0.183)$ & [91.43] \\
\hline \multicolumn{4}{|c|}{ DRG 177} \\
\hline \multirow[t]{2}{*}{19} & $9.56^{* * *}$ & $2.54^{* * *}$ & $3.77^{* * *}$ \\
\hline & $(0.499)$ & $(0.120)$ & [86.05] \\
\hline \multirow[t]{2}{*}{20} & $10.22^{* * *}$ & $2.77^{* * *}$ & $3.69^{* * *}$ \\
\hline & $(0.567)$ & $(0.139)$ & [91.55] \\
\hline
\end{tabular}

Note: Standard errors in parentheses. P-values in brackets. This sample contains only episodes of hospitalization that terminated in discharge to home care or nursing facilities.

${ }^{1} \Phi\left(\gamma_{0}+\gamma_{1} t+\gamma_{2} t^{2}+\mu_{0}\right) * 100$

${ }^{2} \Phi\left(\gamma_{0}+\gamma_{1} t+\gamma_{2} t^{2}+\mu_{-1}\right) * 100$

${ }^{3}$ Hazard ratio: $\frac{\Phi\left(\gamma_{0}+\gamma_{1} t+\gamma_{2} t^{2}+\mu_{0}\right)}{\Phi\left(\gamma_{0}+\gamma_{1} t+\gamma_{2} t^{2}+\mu_{-1}\right)}$. Square brackets contain the p-value from a Wald test for $H_{0}: H R=\frac{\Phi\left(\gamma_{0}+\gamma_{1} t+\gamma_{2} t^{2}+\mu_{0}\right)}{\Phi\left(\gamma_{0}+\gamma_{1} t+\gamma_{2} t^{2}+\mu_{-1}\right)}=1$. 
Table A11: Selected Probit Coefficients by Subgroup, DRG 207 at day $=29$

\begin{tabular}{lcc}
\hline Model \#/Partition & SSO Threshold Day & Preceding Day \\
\hline \hline Model \#1: & $2.96^{* * *}$ & $1.95^{* * *}$ \\
For-profit & $(0.332)$ & $(0.333)$ \\
Not for profit & $2.85^{* * *}$ & $2.12^{* * *}$ \\
& $(0.340)$ & $(0.332)$ \\
\hline Model \#2: & & \\
Kindred and Select & $3.09^{* * *}$ & $2.05^{* * *}$ \\
Other & $(0.322)$ & $(0.324)$ \\
& $2.99^{* * *}$ & $2.17^{* * *}$ \\
Model \#3: & $(0.328)$ & $(0.322)$ \\
After Acquisition & $3.27^{* * *}$ & $2.02^{* * *}$ \\
Before Acquisition & $(0.247)$ & $(0.245)$ \\
Never Acquired & $3.21^{* * *}$ & $2.32^{* * *}$ \\
& $(0.254)$ & $(0.249)$ \\
& $3.13^{* * *}$ & $2.22^{* * *}$ \\
Model \#4: & $(0.246)$ & $(0.242)$ \\
HwH & & $3.41^{* * *}$ \\
Not HwH & $2.36^{* * *}$ & $(0.284)$ \\
& $(0.284)$ & $3.19^{* * *}$ \\
\hline
\end{tabular}

Note: Standard errors in parentheses. 


\section{E Additional Figures for Counterfactual Analysis}

Figure A3 displays the observed (solid line) discharge probabilities over time and the predicted (dashed line) discharge probabilities corresponding to the estimates in column (1) of Table 7. where the horizontal axis in these figures is the number of days relative to the magic day (vertical line) 39 Panel (a) compares the predicted and observed discharge distributions for the entire sample of pooled DRGs while panel (b) focuses on just DRG 207.

Figure A3: Observed and predicted discharge probabilities

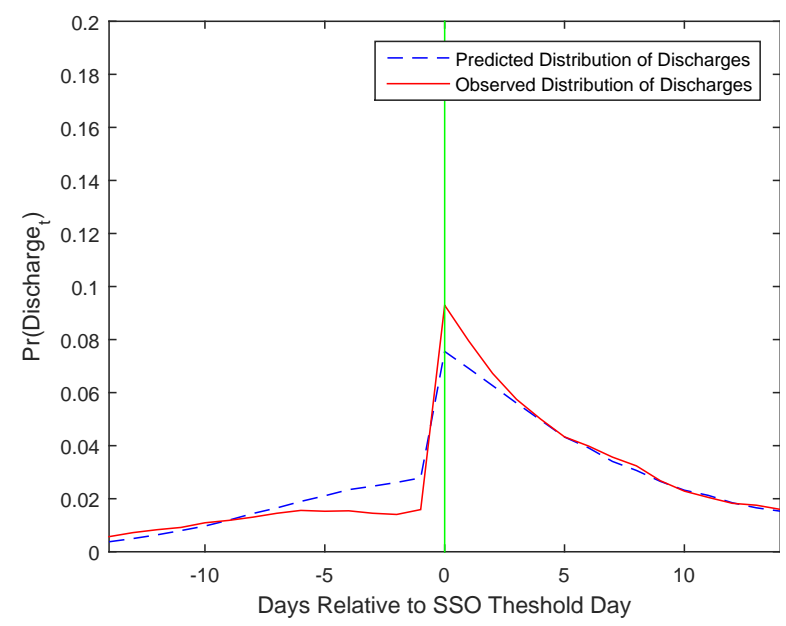

(a) Pooled DRGs

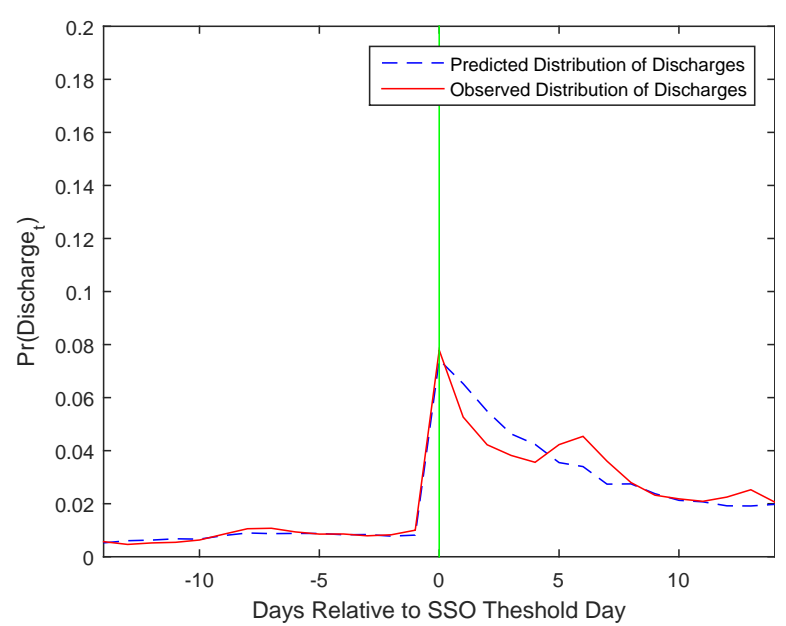

(b) DRG 207

Figure A4 compares the reimbursement schemes we consider in the counterfactual analysis to the current PPS.

\footnotetext{
${ }^{39}$ The predicted discharge probabilities are computed by simulating the model 100,000 times.
} 


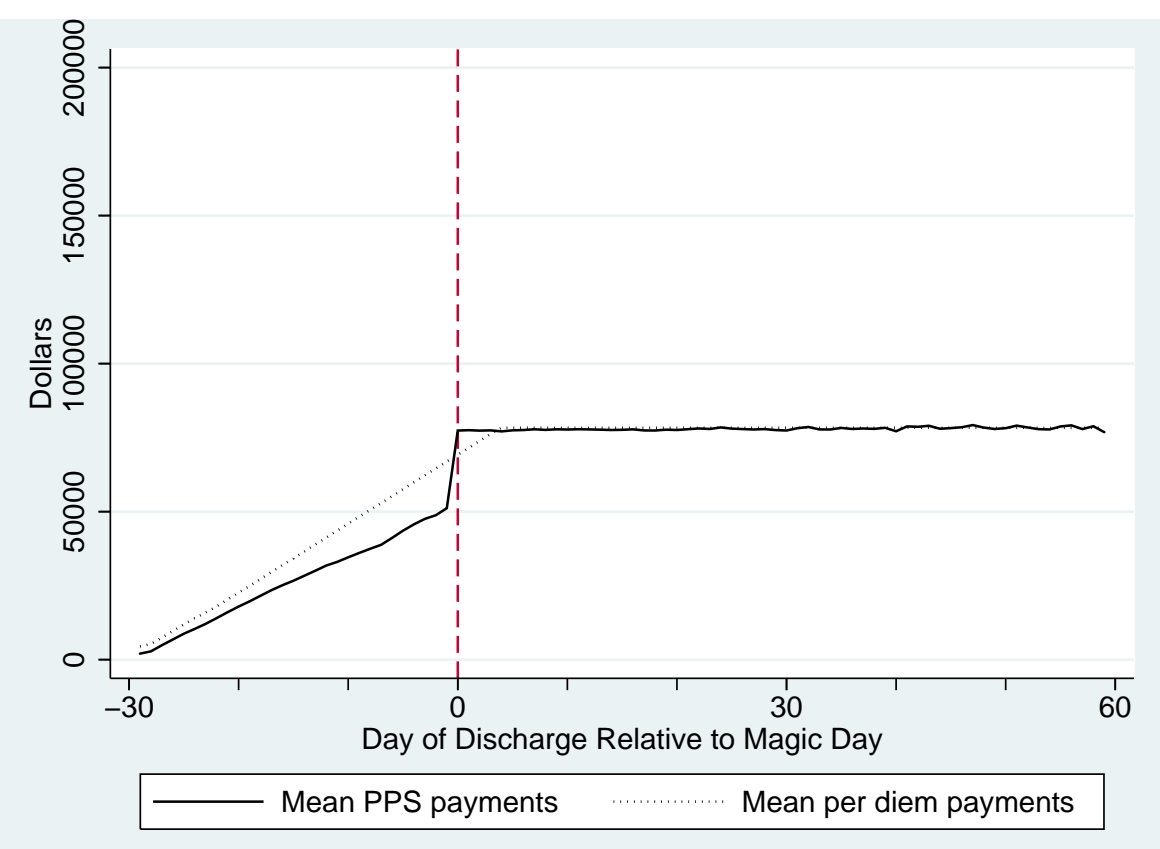

(a) Payments under per-diem counterfactual

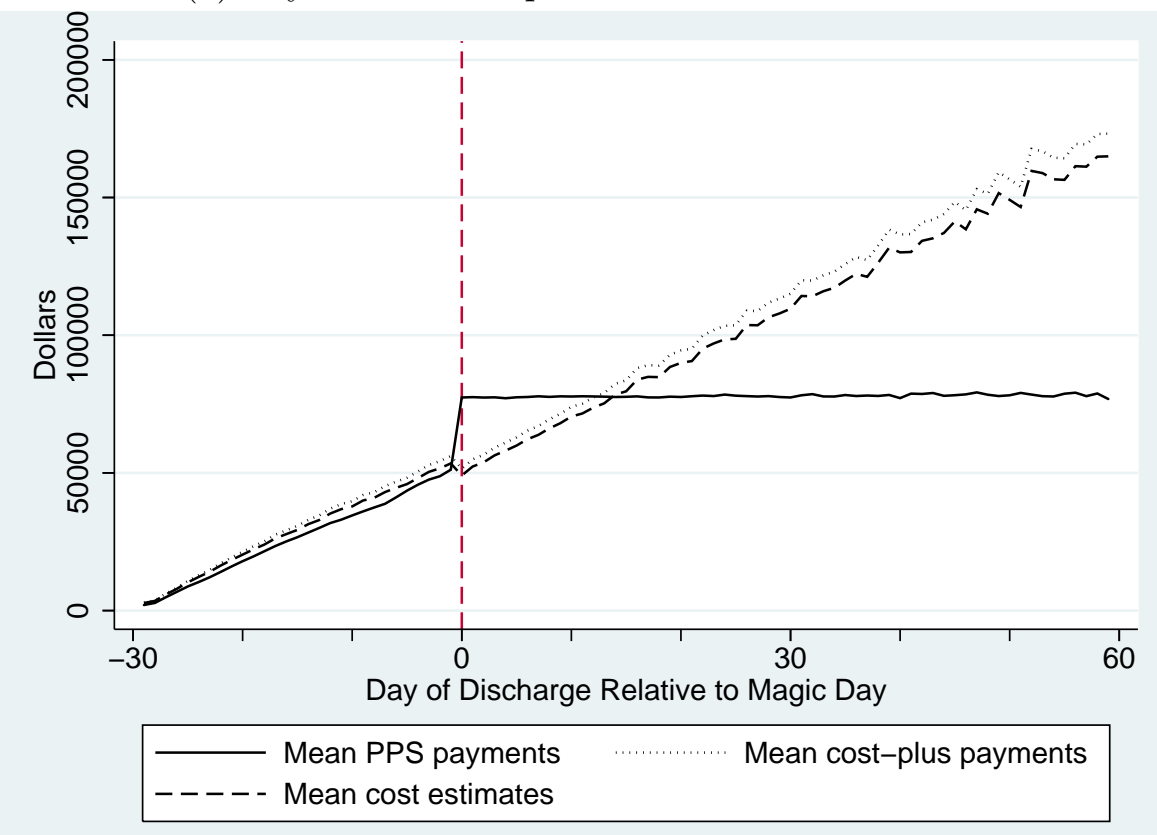

(b) Payments under cost-plus counterfactual

Figure A4: Counterfactual Reimbursement Policies for DRG 207. 